\title{
11. DUCTILE STRAINS IN CLAY-RICH SEDIMENTS FROM HOLE 808C: PRELIMINARY RESULTS USING X-RAY POLE FIGURE GONIOMETRY ${ }^{1}$
}

\author{
Julia K. Morgan, ${ }^{2}$ and Daniel E. Karig, ${ }^{2}$
}

\begin{abstract}
Deformation within accreting and subducting sediments may occur through ductile as well as brittle modes, producing deformation fabrics defined by the preferred orientation of sedimentary particles. The method of X-ray pole figure goniometry is used to determine the clay-mineral fabric in hemipelagic sediments collected from Hole 808C within the Nankai accretionary prism toe during ODP Leg 131. Total finite ductile strains are estimated assuming the theory of March (1932) relating grain preferred orientation to strains.

The resulting strains, adjusted to reflect volume changes in the sediments, suggest that accreting sediments have experienced up to $10 \%$ lateral ductile shortening while subducting sediments show little evidence for any lateral shortening. This suggests that the décollement serves as an important boundary between subducting and accreting sediments in the vicinity of Site 808. Vertical strains obtained here are lower than expected, especially for the deepest samples, possibly due to the effects of bioturbation during primary deposition and compaction, or to the breakdown of the March model at high strains. The results also suggest that sediment response to tectonic stress may vary with position, based on reversals in depth trends for strains and strain parameters at mid-depth. Further work is needed to expand these findings.

This study shows that the method of X-ray pole figure goniometry can be useful for recognizing spatial variations in deformation fabrics and ductile strains in sediments within the toes of accretionary prisms.
\end{abstract}

\section{INTRODUCTION}

Large- and intermediate-scale brittle deformation in accretionary prisms has been well established by seismic reflection profiling across active margins (e.g., Moore et al. 1990) and study of accretionary sediment cores collected during DSDP and ODP Legs (Behrmann et al. 1988; Lundberg and Moore, 1986; Taira, Hill, and Firth, 1991), but the contribution of microscale ductile deformation remains poorly understood. Seismically-imaged thickening of sedimentary packages incorporated into accretionary prisms (Karig, 1986; Moore et al., 1990) points to a significant amount of unresolved diffuse deformation, much of which may be attributed to small-scale features observed in drill cores (Karig and Lundberg, 1990), but some of which may occur at the grain scale as sedimentary particles reorient under stress (Hounslow, 1990). The record of this ductile strain may be preserved in the sediment fabric as clay-mineral preferred orientation.

In this study, the clay-mineral fabric of sediments collected from Hole $808 \mathrm{C}$ during ODP Leg 131 is examined using the method of X-ray pole figure goniometry (Oertel, 1983; Wenk, 1985). Clays of a specific mineralogy will diffract $\mathrm{X}$-rays proportional to the density of grains favorably oriented to the incident X-ray beam. By measuring diffracted intensities for various sample orientations, a fairly complete angular density distribution of clay-minerals can be obtained, which can be used to assess spatial variations in sediment deformation within the hole.

Phyllosilicate minerals are prime candidates for texture studies. Deposition of clay-sediments in marine environments has been shown to produce a highly porous microfabric characterized by randomly oriented domains of clay minerals (Moon and Hurst, 1984; Bennett et al., 1991). During burial, clay minerals tend to be rearranged so that their basal planes lie normal to the direction of maximum shortening (Bennett et al., 1977; Moon and Hurst, 1984; Bryant et al., 1991). Under low stresses, the dominant deformation mechanism is assumed to be independent particulate flow (Borradaile, 1981) or grain bound-

${ }^{1}$ Hill, I.A., Taira, A., Firth, J.V., et al., 1993. Proc. ODP, Sci. Results, 131: College Station, TX (Ocean Drilling Program).

${ }^{2}$ Department of Geological Sciences, Cornell University, Ithaca, New York 14853 , ary sliding (Knipe, 1989), whereby grains mechanically rotate without interacting to produce a tighter packing, expelling pore fluids in the process (Maltman, 1984; Knipe, 1989).

Several models have been put forth to describe particle motions assuming interparticle mechanisms. The motion of particles approximated as ellipsoids of rotation has been predicted by Jeffery (1922) and Gay (1968), while Tullis (1971) has shown that in the limit, as grains become very elongate or tabular, they will rotate passively as if deforming homogeneously with the matrix. This is the model proposed by March (1932; see Oertel, 1985a). Although March assumes an initially uniform orientation distribution of grains, the theory has been extended by Owens (1973) to include any arbitrary starting distributions. Prompted by observations that mechanical rotation may be the dominant strain accomodation process during the early stages of deformation in phyllosilicate-rich rocks (Means and Paterson, 1966; Knipe, 1981), the model has been invoked many times to estimate finite strains in slates, occasionally yielding strain estimates comparable to those obtained from independent strain indicators (Oertel, 1970; Oertel and Curtis, 1972; Tullis and Wood, 1975, Wood et al., 1976).

The application of the March model to define finite strains in phyllosilicate-rich rocks, even at low metamorphic conditions, has been called into question by other studies (Holeywell and Tullis, 1975; Siddans, 1976; Etheridge and Oertel, 1979), and indications that intracrystalline mechanisms, mineral recrystallization, and pressure solution transfer are important factors in the development of phyllosilicate preferred orientation (Etheridge et al., 1974; Etheridge and Lee, 1975; Knipe, 1981; Kanagawa, 1991; others). Under the relatively low temperature and pressure conditions within the toes of accretionary prisms, however, such complications are not likely to be present. Strain during soft-sediment deformation is accommodated primarily through mechanical rotation of grains (Maltman, 1984), closely approximating the requirements of the March model. Consequently, the marine sediments collected from the Nankai accretionary prism during ODP Leg 131 should offer an excellent test of the use of the March model for quantifying ductile strains in porous sediments.

Within the approximately two-dimensional, steady-state system represented by the accretionary prism toe, sedimentary elements progress arcward along specific trajectories determined by their initial 
point of deposition (Karig, 1991). The one-dimensional cross-section provided by Hole $808 \mathrm{C}$ will be intersected by each trajectory, thus permitting an examination of the finite ductile strain record of sedimentary elements along that trajectory. The finite strain preserved within the clay-mineral fabric of the element will reflect both vertical compactive strain acquired during deposition and burial in basin and prism, and tectonic strain applied arcward of the deformation front with unknown orientation. Although the two components cannot be uniquely resolved by this study, the imposition of lateral tectonic strain on uniaxial depositional fabric should produce a distinct signature through the development of anisotropy of clay-mineral densities in the lateral plane, allowing us to document the occurrence and importance of such ductile deformation in both accreting and subducting sediments.

\section{SAMPLE DESCRIPTION}

Nine clay-rich samples were selected for this study from Hole $808 \mathrm{C}$, ranging in depth from 318 to 1137 meters below seafloor (mbsf) (Fig. 1). The samples are generally composed of hemipelagic silty-claystone and are fairly homogeneous as hand samples. Bulk powder diffraction analyses performed on Shikoku Basin hemipelagites from Hole 808C (Michael Underwood, written communication, 1991) indicate that clay minerals, including smectite, illite, kaolinite, and chlorite, comprised $30 \%-40 \%$ of sediment by weight (see Karig, this volume, Fig. 2). Complete analyses were not performed on the particular samples used for this study.

Efforts were made to obtain coherent materials of homogeneous character, away from obvious deformational structures. The microscopic fabric of several samples examined in thin-section demonstrated the fairly homogeneous nature of the sediments. Sections 131-808C-3R-1 and $-24 R-4$, from the Outer Marginal Trench Wedge, and 131-808C-32R-2 and -37R-1, obtained from the trenchto-basin transition and upper Shikoku Basin units respectively, were very similar in thin-section, composed of a fine-grained silt/clay matrix with interspersed silt grains, generally fining downhole. The preferred orientation of clay minerals was only moderately evident, possibly due to low concentrations of clay in the matrix. Most of these samples displayed diffuse zones or channels of apparently slightly greater concentrations or alignment of clay minerals, probably indicative of bioturbation. Sample 808C-21R-4, from the outer marginal trench wedge, contained elongate, sharply bounded domains of dark-gray, very fine-grained, highly oriented clay, yielding nearly uniform extinction angles within $10^{\circ}$ of that of the matrix. The domains, also apparent in hand sample, are believed to be rip-up clasts from semilithified muds, transported downslope and redeposited in the trench.

Sections 131-808C-56R-2, -61R-5, -70R-2, and -89R-1 were collected from the more uniform Lower Shikoku Basin. Although mottling evident in hand samples suggested significant bioturbation, the sediments appeared very homogeneous in thin-section, lacking the disturbed zones apparent in the upper samples. Sediments were again composed of very fine-grained silt/clay matrix, with fewer coarse silt grains than above, almost absent in Section 131-808C-70R2. Clay minerals in Section 131-808C-70R-2 appeared to be very highly oriented, perhaps due to fine grain-size and high clay concentration. Both Sections 131-808C-70R-2 and -89R-1, collected below the décol-lement, displayed fissility as pervasive subhorizontal cracking, and some color variations in hand sample, which did not correspond to any visible variation in texture in thin-section.

\section{DATA COLLECTION}

\section{Sample Preparation}

The sediment samples are quarter-round cores oriented with respect to vertical. As shown in Figure 2, a right-handed reference frame is imposed on the uncut sample such that the $z$-axis points down and the $x$ - and $y$-axes coincide with the cut surfaces. Samples were oriented with respect to magnetic north using paleomagnetic orientations determined for coherent core segments from which samples were obtained (Taira, Hill, and Firth, 1991). The direction of magnetic north could not be determined uniquely due to ambiguity about the configuration of the quarter-round core (Fig. 2).

Sections of the sample, $3-5 \mathrm{~mm}$ thick, were cut perpendicular to the $x$ - and $y$-axes using a water-lubricated, diamond-impregnated wire saw. Pore water was exchanged with ethanol by immersion over a period of 3 weeks, during which time ethanol was replaced every 3 days until no water remained. The ethanol was then removed and LR WHITE resin added to cover the section. The sections were placed under vacuum for $1 \mathrm{hr}$ to remove any residual air from the pore spaces, then chilled undisturbed in resin for $2-4$ weeks to allow complete penetration. Finally, the sample containers were sealed to prevent exposure to free air, and cured at $60^{\circ} \mathrm{C}$. for $24 \mathrm{hr}$.

Following impregnation, the surface of the X-ray section was polished, removing material that may have been disturbed during cutting. The prepared surface was affixed to an aluminum chip with a central hole provided for passage of the beam, aligning the sample axes with the edges of the chip. The section was then trimmed and polished to the finished thickness of 100-200 $\mu \mathrm{m}$.

Ethanol has been shown to introduce no effects during claysediment preparation (Prior and Behrmann, 1990), and has been used in preparation of samples for higher resolution electron microscopy work (Baerwald et al., 1991). Although Baerwald and others have reported distortion and warping using LR WHITE resin, no such effects were observed when the above method was closely followed. Incomplete curing and flaky surfaces did occasionally develop if the sample was incompletely sealed or impurities were present during curing.

It was determined that the preceding method of sample preparation introduced no measurable strain, as X-ray scans for different sections of a given sample yielded very similar density distributions.

\section{X-ray Pole Figure Goniometry}

$\mathrm{X}$-ray pole figure goniometry can be performed in two modes: reflection and transmission (Cullity, 1978). In reflection mode, X-rays are diffracted by grains near the surface of the sample. Transmission mode, wherein X-rays diffract from interior grains, has been preferred for phyllosilicate fabric analysis, because of the possibility of damage to surface grains during sample preparation (Oertel, 1983).

Diffracted intensities obtained during X-ray transmission scans are augmented by background radiation and attenuated by material absorption and beam defocusing varying with tilt (Cullity, 1978). If background radiation is predominately due to incoherent scattering, then it will vary with the volume of diffracting material in the same manner as the diffracted intensities (Bragg and Packer, 1963), and can be described as a constant volumetric coefficient, $b$ (Chen, 1991). Intensities measured at the Bragg angle, $\theta$ can therefore be described by the generalized equation

$$
I_{d}(\alpha, \beta)=\left[\rho^{\prime}(\alpha, \beta)+b\right] C(\mu, \theta, t, \alpha)
$$

where $I_{d}(\alpha, \beta)$ is the intensity of the Bragg reflection in the direction defined by $\alpha$, or tilt, and $\beta$, or azimuth, $\rho^{\prime}(\alpha, \beta)$ is the density of poles to the diffracting crystal plane in direction $(\alpha, \beta), b$ is the constant background radiation, and $C(\mu, \theta, t, \alpha)$ is a generalized correction ratio for absorption and tilt depending on Bragg angle $\theta$, thickness $t$, and linear absorption coefficient $\mu$ (Cullity, 1978).

\section{Goniometer Configuration and Data Acquisition}

Transmission scans were run on a Scintag SPF-105 four-axis pole-figure goniometer located at the Cornell Material Science Center's (MSC) X-ray facility, with a diffractometer circle fixed at $250 \mathrm{~mm}$, solid-state detector system fixed to receive $\mathrm{Cu} k \alpha$ wave- 
A

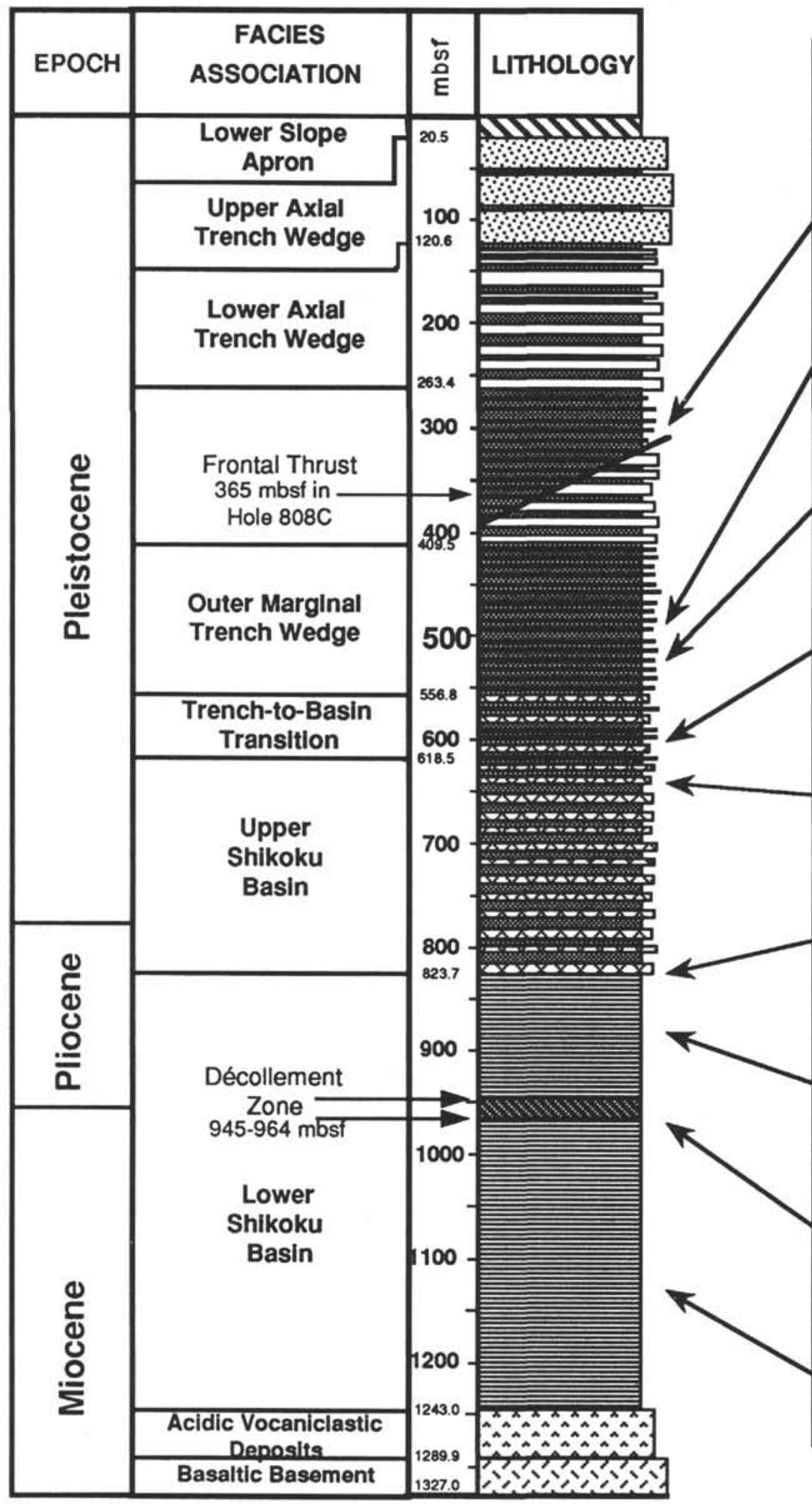

B

\section{SAMPLE AND DESCRIPTION}

808C-3R-1, 88-92 cm (318 mbsf)

Outer Marginal Trench Wedge: Med.-gray, fine-grained silty-clayst.; homogeneous in hand sample; diffuse zoning in thin-section. Above Frontal Thrust.

808C-21R-4, 114-118 cm (497 mbsf) Outer Marginal Trench Weidge: Med.-gray, finegrained silty-clayst. with $\mathrm{mm}$. scale dark-gray, very fine-grained clayst. clasts; laminated bands of light-gray clay. Within Protothrust Zone. 808C-24R-4, 108-112 cm (526 mbsf) Outer Marginal Trench Wedge: Med.-gray, fine-grained silty-clayst.; homogeneous in hand sample. Within Protothrust Zone.

808C-32R-2, 143-147 cm (600 mbsf) Trench-to-Basin Transition: Light-gray, fine-grained silty-clayst.; homogeneous in hand sample; diffuse zoning in thin-section. Within Protothrust Zone.

808C-37R-1, 66-70 cm (646 mbsf) Upper Shlkoku Basin: Light-gray, finegrained,silty-clayst.; homogeneous in hand sample; diffuse zoning in thin-section. Within Protothrust Zone.

808C-56R-2, 29-33 cm (830 mbsf)

Lower Shlkoku Basin: Homogeneous, med.gray, fine-grained silty-clayst. Within Protothrust Zone

808C-61R-5, 102-107 cm (884 mbsf) Lower Shikoku Basin: Homogeneous, med.gray, fine-grained silty-claystone. Within Protothrust Zone

808C-70R-2, 52-56 cm (965 mbsf)

Lower Shikoku Basin: Fairly homogeneous, dark-gray to dark-green, fine-grained clayst. with reddish mottling. Immediately below décollement.

808C-89R-1, 8-12 cm (1137 mbsf) Lower Shlkoku Basin: Dark-green, fine-grained claystone with reddish banding;. Below décollement.

Figure 1.A. Stratigraphic section for Site 808 (Taira, Hill, and Firth, 1991), showing position of frontal thrust and décollement in Hole 808C. B. Sample identification and description for samples used in this study. Depths of recovery are indicated by arrows. 


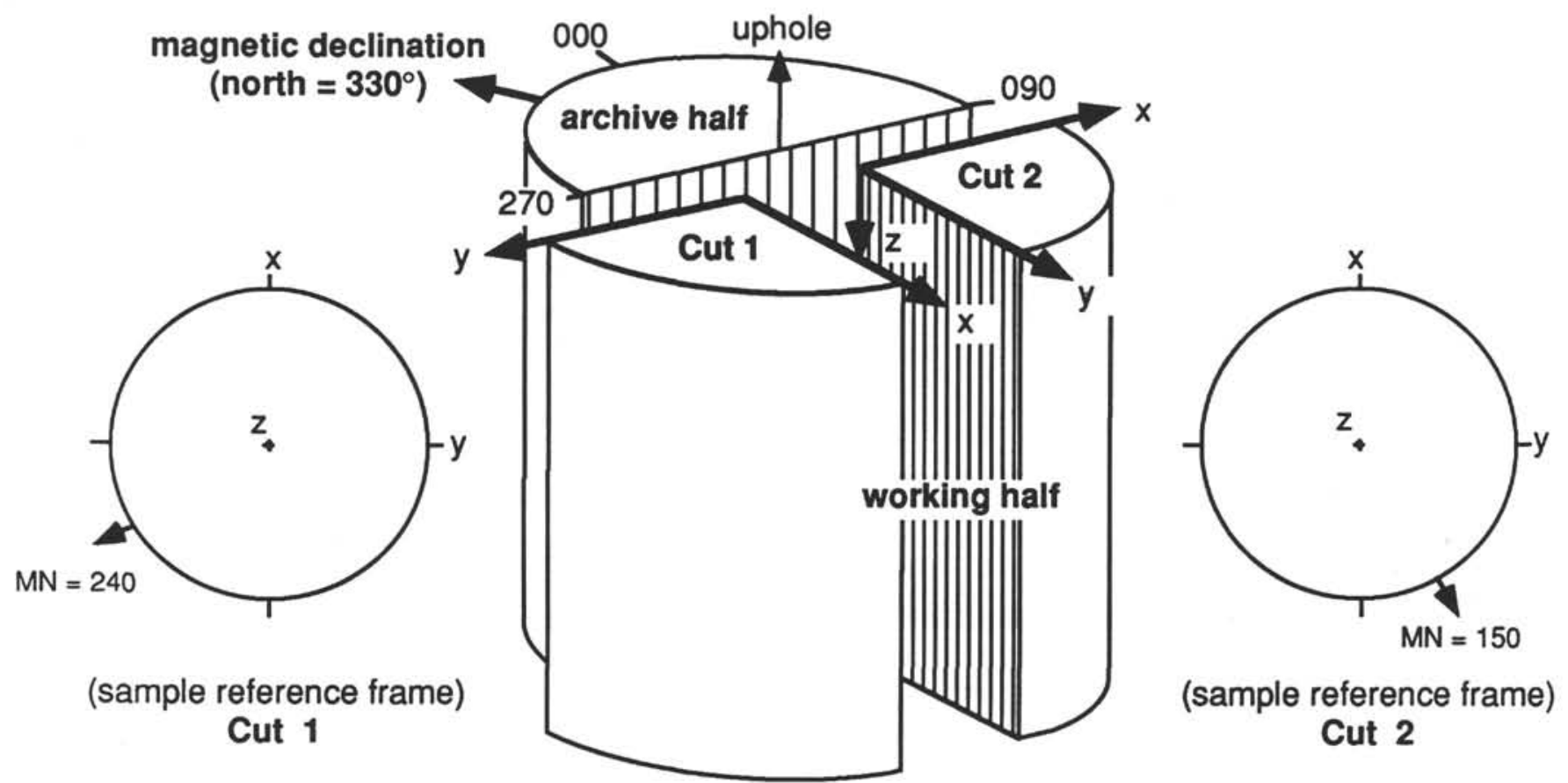

(archive-half reference frame)

Figure 2. Relationship between sample coordinates $(x, y$, and $z)$, archive-half reference frame (000-359, down) and paleomagnetic declination (magnetic north, shown for Sample 131-808C-21R-4, 114-118 cm). Two configurations are possible for quarter-round cores used in this study (Cut 1 and Cut 2), yielding two possible orientations for magnetic north as shown on sample projections.

lengths, and generator set to $45 \mathrm{kV}$ and $40 \mathrm{~mA}$. The incident beam from the line-focus $\mathrm{Cu}$ source was collimated to an initial diameter of $1 \mathrm{~mm}$, producing a beam with a slightly elliptical cross-sectional area. The four independent stepping-motors were controlled by a DEC microcomputer using modified Scintag data-acquisition software.

As can be seen in the diffraction pattern for the cross-section of 808C-24R-4 (Fig. 3), intensities of major clay mineral basal reflections were quite low relative to apparent background in these samples, in part due to small grain size and mixed clay composition containing low concentrations of individual clay components. The strongest unhindered reflection corresponds to the $(002)$ plane for kaolinite $(\mathrm{d}=$ $7.17 \AA, 2 \theta \approx 12.3^{\circ}$ for $\mathrm{Cu} k \alpha$ radiation), which overlaps with the (004) reflection for chlorite (Moore and Reynolds, 1989). Transmission scans were performed using this reflection, assuming without proof that chlorite and kaolinite preferred orientations will be similar in these sediments. As the position of this reflection varies slightly among samples due to varying section thickness and lithology, a normal diffraction scan was performed for a small range of $2 \theta$ prior to the pole figure scan to determine the proper Bragg angle of reflection. Uncertainties in measured intensities introduced by the low signal-to-noise ratio were minimized by long-duration scans ( 12 to $14 \mathrm{hr}$ on average), counting for about $80 \mathrm{~s}$ at each node.

Diffracted intensities, $I_{d}(\alpha, \beta)$, are collected by tilting the sample with respect to the bisector of the incident and diffracted beam at $5^{\circ}$ increments of tilt, $\alpha$, between $0^{\circ}$ and $35^{\circ}$, and rotating about an axis normal to the section at $10^{\circ}$ increments of azimuth, $\beta$ (Cullity, 1978; Wenk, 1985). Apparent background is measured at $30^{\circ}$ increments of azimuth at $2 \theta$ angles of $10.5^{\circ}$ and $15^{\circ}, I_{10}(\alpha, \beta)$ and $I_{15}(\alpha, \beta)$, respectively. The counting nodes plot along small circles on an equal-area projection centered about the normal to the transmission section, shown in the goniometer reference frame in Figure 4(A) and transformed into sample reference frame in Figure 4(B). Each scan yields a $70^{\circ}$-wide band of data centered about the plane of the section, which represents the $0^{\circ}$-tilt position. By overlapping two perpen- dicular sections (Fig. $4(\mathrm{C})$ ), coverage of the projected pole figure is nearly complete.

\section{Background Correction}

The measurement of background in diffraction studies of claymineral mixtures is complicated by several factors. Offset of basal reflections due to interlamellar complexes and interstratified clay minerals, and broadening of clay reflections due to finite crystal size and disorders in layer stacking, produce a continuous range of diffraction effects such that true background may not be observed at any point in the diffraction pattern (Brindley, 1980). Adequate estimation of the background must be made, however, to obtain clay-mineral preferred orientation, especially when the background contribution to total intensities is quite high relative to diffracted intensities (Fig. 3).

To complicate matters, scans performed on the MSC X-ray goniometer with sample holder but no sample indicate that background is not uniform, but strongly depends on the position of the sample mount with respect to the beam. Figure 5 clearly shows the variation in background, with a maximum near azimuth, $\beta=0^{\circ}$ and decreasing to about $85 \%$ maximum intensity at $\beta=180^{\circ}$. This indicates variations in air scatter with sample orientation, introducing an additive contribution to total intensities that must be eliminated.

To analyze dependence of apparent background on clay-mineralpreferred orientation, $I_{10}(\alpha, \beta)$ and $I_{15}(\alpha, \beta)$ are plotted against $I_{d}(\alpha$, $\beta$ ), yielding several subparallel, linear clusters (Fig. 6), offset vertically due to variation in X-ray absorption with tilt. The dependence of apparent background on clay-mineral preferred orientation is given by the slope of the clusters, which should be a function of the proportion of diffracted X-rays in the measured intensities and the absorption coefficient, $\mu$, of the material.

If the absorption coefficient for the material is not constant as assumed for most materials (Cullity, 1978) but a symmetric secondorder tensor as suggested by Chen (1991) for slates, the slopes of the 


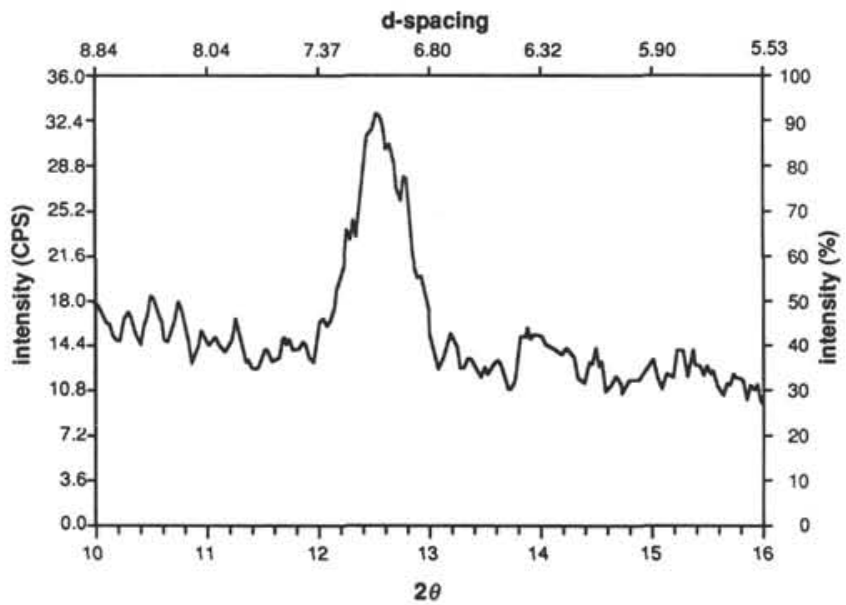

Figure 3. Diffraction pattern for Sample 131-808C-24R-4, 108-112 cm, $x$-plane, showing reflection for $(002)$ kaolinite plane at $2 \theta \approx 12.5^{\circ}$. Intensities are plotted in counts per second (cps). Notice the relatively high apparent background in the vicinity of the reflection.

clusters need not be constant within a given data set. The near-parallel relationship apparent here, however, argues for a nearly constant absorption coefficient, consistent with the relatively low degree of preferred orientation expected for mildly deformed sediments.

Both data sets show some correlation with clay-mineral preferred orientation, but intensities measured at $2 \theta=15^{\circ}$ show much less dependence than those measured at $2 \theta=10.5^{\circ}$, offering a close approximation of true background at that diffraction angle. However, background obtained at $15^{\circ}$ may not be representative of background for the kaolinite (002) reflection angle as background becomes nonlinear and increases rapidly at the low $2 \theta$ range where useful basal clay reflections occur (Moore and Reynolds, 1989).

An alternate method of background determination proposed by Chen and Oertel (1991) employs a nonlinear numerical procedure for estimating true background iteratively along with March strain determination. This will not remove any additive background effects introduced by the geometry of the sample or sample holder as mentioned above, but since such contributions should be similar within $2^{\circ}-3^{\circ}$ of $2 \theta$, taking the difference between $I_{d}(\alpha, \beta)$ and $I_{15}(\alpha, \beta)$ should minimize the effects. The difference between true and apparent background, $\Delta b$, should be constant and can be found iteratively.

\section{Absorption Correction}

To obtain pole densities, measured intensities must be corrected for varying absorption of X-rays with tilt. If the absorption coefficient, $\mu$, can be reliably measured then an analytical correction for tilt can be applied (Cullity, 1978, equation (9-10); Chen, 1991). Due to difficulties in reproducibly measuring absorption coefficients for these samples, an empirical correction based on apparent background was used, following the recommendations of Bragg and Packer (1963, 1964). If background results primarily from incoherent radiation, as argued by Bragg and Packer (1963) and Chen (1991), then ratios of background intensities can be used as correction factors. The correction factor, $\mathrm{C}(\mu, \theta, \mathrm{t}, \alpha)$, is given by the ratio of average background at some tilt to the average background at 0 -tilt, $R(\alpha)$ :

$$
R(\alpha)=\frac{I_{15}^{a v g}(\alpha)}{I_{15}^{a v g}(0)}
$$

Although the additive contribution to background introduced by the asymmetry of the sample mount should not be included in this calculation, the resulting ratios will probably vary slightly when this effect is not completely removed. This method yielded more consistent density distributions for different sections of a given sample than analytically-derived corrections, and was therefore chosen as the best method for correcting X-ray intensities for absorption.

\section{REDUCTION TO MARCH STRAINS}

\section{March Model}

The theory developed by March (1932) relates the distribution of oriented linear and planar elements within a homogeneously deforming volume to the state of strain (see Lipshie, 1984; Oertel, 1985). The final pole distribution provides only the distortion component of strain, as isotropic volume changes will not affect the angular density distribution. Thus, March strains as defined here represent constantvolume strains. For the case of elements with an initial random distribution, the angular density distribution of poles, $f(\alpha, \beta)$, resulting from a linear transformation of material elements by the deformation gradient tensor F, takes the form (Owens, 1973):

$$
f(\alpha, \beta)=\frac{1}{|\mathbf{F}|} \rho_{0}[\lambda(\alpha, \beta)]^{3 / 2}
$$

where $\rho_{0}$ represents the uniform density of particles or poles in the undeformed state, $\mathbf{F}$ is the deformation gradient tensor, whose determinant, det $\mathbf{F}$, represents volume change, and $\lambda(\alpha, \beta)$ is the quadratic elongation (Means, 1976) in direction $(\alpha, \beta)$. In the case of planar markers such as phyllosilicate minerals, $\lambda(\alpha, \beta)$ represents the squared radius of the reciprocal strain ellipsoid (Ramsay and Huber, $1983)$ in direction $(\alpha, \beta)$ :

$$
\frac{1}{\lambda(\alpha, \beta)}=m_{i j} I_{i} I_{j}(i, j=1,2,3)
$$

(summation assumed on repeated indices) where $m_{i j}$ are the symmetric coefficients $\left(\mathrm{m}_{i j}=\mathrm{m}_{j, i}\right)$ of the constant-volume, reciprocal strain ellipsoid in the goniometer reference frame, and $I_{i}$ are the direction cosines for the vector in direction $(\alpha, \beta)$. Note that the right side of equation (4) describes the transformation of the poles to planes in the deformed state, and therefore bears an inverse relationship to the strain ellipsoid describing the transformation of material points (Lipshie, 1984).

Combining equations (3) and (4), and assuming constant volume strain (det $\mathbf{F}=1)$, gives

$$
f(\alpha, \beta)=\rho_{0}\left[m_{i j} I_{i} I_{j}\right]^{-3 / 2}(i, j=1,2,3)
$$

If $f(\alpha, \beta)$ is known, then equation (5) contains seven unknown parameters describing the angular density distribution and background: six coefficients $m_{i j}$, five of which are independent due to the constant volume constraint, and the initial pole density $\rho_{0}$ A coordinate transformation of the ellipsoid described by $m_{i j}$ into the principal reference frame for the ellipsoid yields the directions and magnitudes of the principal radii of the reciprocal strain ellipsoid. Inverting the principal radii of the reciprocal strain ellipsoid gives the principal radii of the material strain ellipsoid, or principal linear stretches, $S_{i}=$ $1+\varepsilon_{i,}$ where $\varepsilon_{i}$ is the principal strain (Means, 1976). The principal axes of the two ellipsoids coincide.

\section{Numerical Estimation of March Strains}

To calculate constant-volume March strains, principal X-ray intensities, $I_{d}(\alpha, \beta)$ are corrected for absorption and approximate background, $I_{15}(\alpha, \beta)$ to give corrected intensities $I_{c}(\alpha, \beta)$ :

$$
I_{c}(\alpha, \beta)=\frac{I_{d}(\alpha, \beta)-I_{15}(\alpha, \beta)}{R(\alpha)}
$$

Equating $\rho^{\prime}(\alpha, \beta)$ with $f(\alpha, \beta)$ and defining the constant difference in true and estimated background, $\Delta b=b-I_{15}(\alpha, \beta) / R(\alpha)$, equations (5) and (6) become 


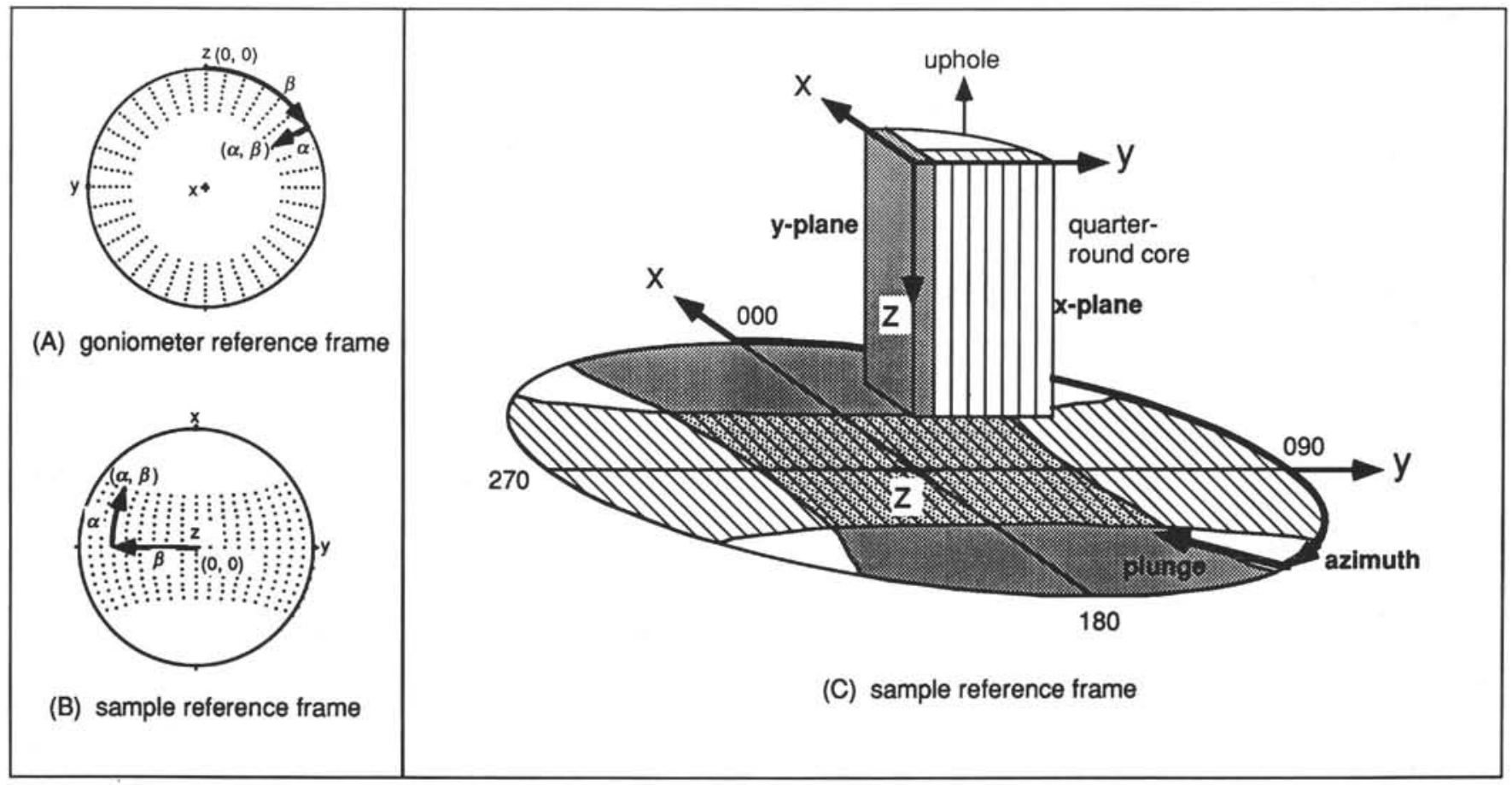

Figure 4. Lower-hemisphere, equal-area projection of directional data, shown in the goniometer reference frame (A) and sample reference frame (B), where $\alpha$ measures the tilt of the sample away from the bisector of the incident and diffracted beams, and $\beta$ is rotation about the normal to the section. The sample coordinates are indicated by $x, y$, and $z$. Data from the two perpendicular transmission scans are superimposed in $(\mathbf{C})$ to provide nearly complete coverage of the projected sphere. Orientations of principal strain axes are represented by azimuth and plunge in the sample reference frame.

$$
I_{c}(\alpha, \beta)=\rho_{0}\left[m_{i j} I_{i} I_{j}\right]^{-3 / 2}+\Delta b^{\prime}(i, j=1,2,3)
$$

This defines a nonlinear system of equations with seven unknowns: $\rho_{0}$, the uniform density of poles in the undeformed state, five independent coefficients to the reciprocal strain ellipsoid, $\mathrm{m}_{i j}$, and a constant background difference $\Delta b$. The method of calculating March strains is modified from Chen and Oertel (1991), employing a nonlinear least-squares solution using the Marquardt-Levenberg method (Press et al., 1989) to iteratively best fit the seven parameters.

The solution generally converges to a background difference close to zero. Plotting iterated and apparent background for all samples against one another (Fig. 7) shows that iterated background values tend to fall near a line defined by $b=0.91 \cdot I_{15}^{\text {avg }}(0)$ (filled diamonds), however a significant number of points lie below the line (open diamonds). Earlier attempts at numerical reduction using less reliable absorption corrections converged to erroneously low background values, suggesting background determination in this manner is very sensitive to the shape of the intensity distribution and may not be dependable. In fact, background tends to increase nonlinearly for lower values of $2 \theta$ and is very likely greater in the vicinity of the reflected peak than at higher $2 \theta$ angles.

The effect of erroneously low background estimates would be to underestimate March strains. Recognizing this possibility, but acknowledging the lack of better methods of background estimation, March strains were calculated using two background estimates: (1) background fixed to $91 \%$ of $I_{15}(0, \beta)$, and (2) background iteratively determined. The fixed background yielded more consistent strains between perpendicular sections and was selected as the more reliable background estimation for discussion, but results from both methods are tabulated in Table 1.

Solutions to equation (7) were obtained for individual data sets, as well as combined perpendicular data sets. For the numerical reduction of the combined data sets, the two scans were scaled in multiples of random distribution (m.r.d.) determined from the numerical reduction of the independent scans, transformed into the common sample reference frame (Fig. 4C), and rotated into coincidence to account for slight alignment errors.

\section{RESULTS}

March strains calculated for individual and combined data sets are given in Table 1 for background held fixed as well as determined iteratively. Absorption and background corrected (assuming 91\% apparent background) intensities for perpendicular sections are contoured in m.r.d., and superimposed in Figure 8 in sample coordinates. The best-fit complete pole figure calculated from equation (7) is also shown contoured in m.r.d. Several figures show a very close fit between perpendicular sections, specifically for Sections 131-808C$3 R-1,-21 R-4,-24 R-4,-56 R-2$, and -70R-2, arguing that the corrections to the data were appropriate. The poor fit evident for other Sections, most notably $131-808 \mathrm{C}-61 \mathrm{R}-5$ and $-89 \mathrm{R}-1$, can probably be attributed to uncertainties inherent in the data collection and correction, as well as sample alignment errors. Results obtained for the combined data sets presumably provide a closer estimate to true pole distribution.

The following observations follow from Figure 8: (1) The pole figures display near-orthorhombic symmetry as expected for the homogeneous deformation of an originally random distribution of poles. (2) With rare exception, the maximum pole density, which corresponds to the minimum strain or maximum shortening direction, is consistently subvertical as would be expected for depositional fabric produced by uniaxial consolidation. (3) Maximum pole densities range from 1.32 to 2.18 m.r.d. but show little systematic variation in intensity with depth. (4) The eccentricity of the projected pole distribution, indicative of the degree of lateral ductile shortening, does show some variation with depth, tending to be most 


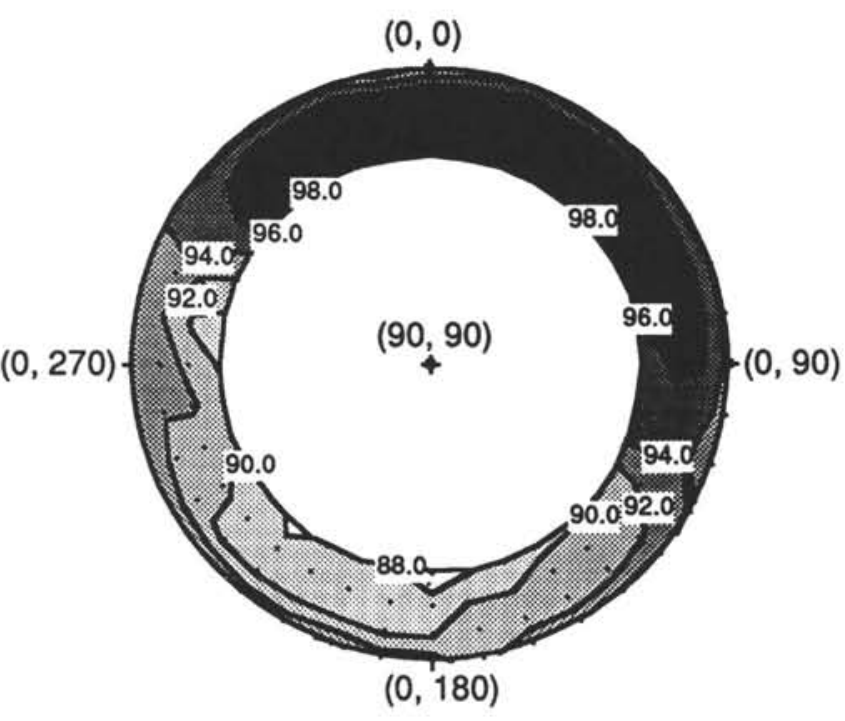

goniometer reference frame

Figure 5. Lower-hemisphere, equal-area projection of nonuniform background in the goniometer reference frame, obtained by performing a scan in transmission mode without a sample. Notice the asymmetry in background indicated by the intensity maximum near $(0,0)$ and minimum at $(180,0)$. Nonuniform background is attributed to air scatter produced by changes in the sample mount position relative to the $\mathrm{X}$-ray beam.

eccentric for Samples 131-808C-32R-2 and -37R-1 at mid-depth, and most concentric for Samples 131-808C-70R-2 and $-89 \mathrm{R}-1$ below the décollement.

Linear stretches listed in Table 1 record only the distortion component of strain, as volume was assumed constant throughout the development of the theory. Shipboard-measured porosities, however, show an overall volume decrease with depth throughout Hole $808 \mathrm{C}$ (Taira, Hill, and Firth, 1991). Correcting March strains for volume change requires making several assumptions about the strain state in the prism: (1) plane strain conditions exist in the prism, based on the extraordinary linearity of features observed in surface expression of the seafloor and the dominant NE-SW strike of deformation structures observed in the cores (Taira, Hill, and Firth, 1991), and (2) total finite strains within the toe are non-extensional (although some vertical extension may occur during tectonic deformation overprinting contractive vertical strains imposed during burial). Maximum strain should therefore be oriented parallel to the trench and represent a direction of zero strain. To test this assumption, paleomagnetic determinations for magnetic north, where available (black arrows on perimeter of pole figures, Fig. 8), are compared with the directions of axes of minimum pole density (coincident with maximum strain axes). Sections 131-808C-3R-1, -21R-4, -56R-2, and -61R-5 suggest that the geographic trend of the axis of minimum pole density lies between $040^{\circ}$ and $064^{\circ}$, close to the $045^{\circ}$ azimuth of the Nankai Trough in the vicinity of Site 808 . The fit is not as good for Section 131-808C-37R-1, and lateral pole densities for 808C-70R-2 are too similar to uniquely define the axis. This limited information suggests that assumptions (1) and (2) may be valid.

If the assumptions are correct, the volume-corrected maximum stretch, $S_{1}^{\prime}$ can be fixed to unity, and all other stretches can be normalized accordingly: $S_{i}^{\prime}=S_{i} / S_{1}$. Principal strains calculated from the normalized stretches $\left(\varepsilon_{i}=S_{i-1}^{\prime}\right)$ are plotted against depth in Figure 9 using the convention that contractive strains are negative. The large circles represent strains calculated from combined perpendicular sections, and the error bars indicate the range of strains obtained from the individual data sets. Maximum strain, $\varepsilon_{1}$ plots at zero by the normalizing assumption. The magnitude of the near- vertical minimum strain, $\varepsilon_{3}$, does not increase with depth as much as expected based on the steady decrease in porosity throughout the hole. In fact, $\varepsilon_{3}$ appears to increase from -0.3 to -0.2 through Section 131-808C-37R-1, then decrease in two steps to below the décollement. The anomalously low magnitude of -0.35 for $131-808 \mathrm{C}-24 \mathrm{R}-4$ is not understood, but is also reflected by the high maximum density in Figure $8 \mathrm{C}$. The trend in $\varepsilon_{2}$, presumed perpendicular to the trench and indicative of lateral shortening, is more subtle and enigmatic, increasing to about 0.10 mid-depth, then decreasing slightly to Section 131-808C-61R-5, and is near zero below the décollement. It is possible that the low vertical strains reflect vertical extension induced by lateral shortening, overprinting primary compactional shortening, but this explanation is unlikely below the décollement where lateral shortening is determined to be near zero.

If the low magnitude of vertical shortening is a consequence of vertical extension accompanying lateral shortening, then volume strains determined from normalized strains and from shipboard porosities should match. Volume strains obtained from the normalized stretches, $\Delta_{m}$ are given as

$$
\Delta_{m}=\frac{V}{V_{0}}-1=\left[S_{1}{ }^{\prime} S_{2}{ }^{\prime} S_{3}{ }^{\prime}\right]-1,
$$

where $V$ and $V_{0}$ are the final and initial volumes, respectively. Volume strains calculated from shipboard porosities, $\Delta_{\mathrm{o}}$ are

$$
\Delta_{\phi}=\frac{V}{V_{0}}-1=\frac{\phi_{0}-\phi}{100-\phi},
$$

where $\varnothing$ and $\emptyset_{0}$ are final and initial porosities, respectively. In the absence of lateral shortening, i.e., under uniaxial strain conditions, $\Delta_{\emptyset}$ would be equivalent to vertical shortening. Initial porosity is assumed to be $65 \%$ based roughly on regression of porosities collected at Site 808 above the décollement (Taira, Hill, Firth, et al., 1991, Table 23, p. 201), although this is certainly not realistic for all lithologies observed in the core. $\Delta_{m}$ and $\Delta_{\vartheta}$ are plotted against depth in Figure 10, with $\Delta_{\mathrm{m}}$ falling between -0.4 to -0.25 , well above the field of porosity-derived volume strains for most of the samples, and showing very little overall change with depth. As a result, the difference between the two volume trends increases with depth. Although the sampling is too small, the four data points below 800 mbsf suggest two sets of data points decreasing with depth, discontinuous across the décollement, reminiscent of the distribution of porosity with depth.

Rotation of principal strain axes may occur during tectonic deformation as a result of either non-coaxial strain or rigid rotation. This would be demonstrated by tilting of the initially horizontal plane containing the maximum and intermediate strain axes. Average dips for each set of perpendicular scans for a given sample are plotted against depth in Figure 11. The error bars show the range of values determined for the individual scans, representing uncertainties introduced during sample mounting and polishing. Overall there is a very subtle increase in dip to about $20^{\circ}$ at a depth of about $700 \mathrm{mbsf}$, and a possible decrease below, although the variations may well be within the uncertainty of the measurements.

Several scale-independent strain parameters were determined for these samples, comparable to quantities often used to describe findings of physical properties, fabric, and mechanical studies (Owens, 1974; Owens and Bamford, 1976):

(1) Total anisotropy, $A_{3}$, is a measure of the magnitude of strain, given by

$$
A_{3}=\frac{S_{1}{ }^{\prime}-S_{3}{ }^{\prime}}{S_{1}{ }^{\prime}+S_{2}{ }^{\prime}+S_{3}{ }^{\prime}} \cdot 300 \% .
$$

(2) Lateral anisotropy, $A_{2}$ is an analogous term describing the eccentricity of the subhorizontal, elliptical plane containing the maximum and intermediate axes of the strain ellipsoid: 
Table 1. Principal stretches, $S_{i}$, and orientations (azimuth and plunge) determined using X-ray pole figure goniometry on samples collected from Leg 131, Hole 808C. Orientations are given in the sample reference frame.

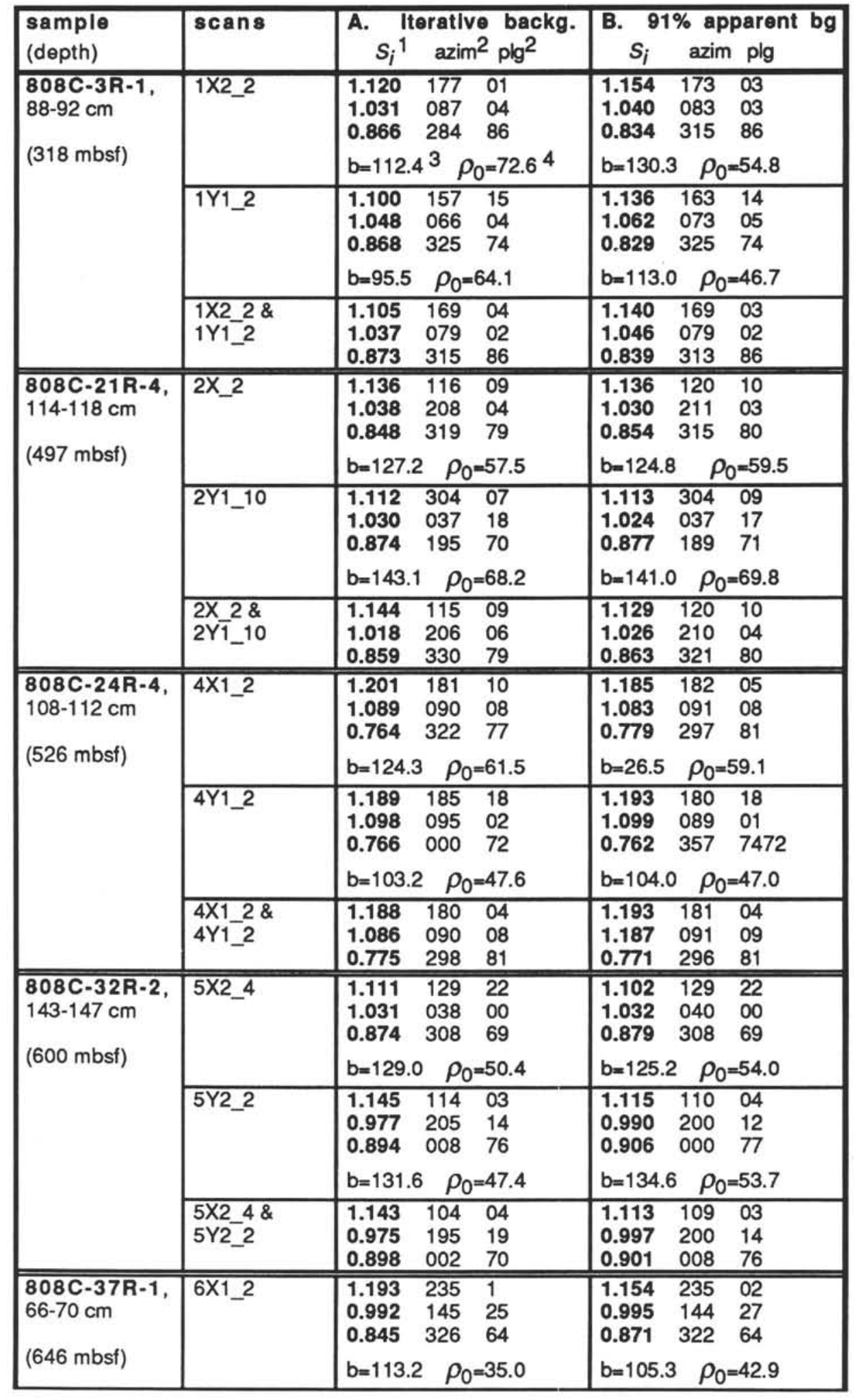


Table 1 (continued).

\begin{tabular}{|c|c|c|c|}
\hline \multirow[t]{2}{*}{$\begin{array}{l}808 \text { C-37R-1, } \\
66-70 \mathrm{~cm} \\
\text { (cont.) }\end{array}$} & 6Y_2 & \begin{tabular}{lcc}
1.195 & 089 & 99 \\
1.029 & 179 & 13 \\
0.888 & 360 & 77 \\
b $=98.0$ & \multicolumn{2}{c}{$\rho_{0}=55.9$}
\end{tabular} & $\begin{array}{lll}1.115 & 252 & 2 \\
1.031 & 162 & 12 \\
0.870 & 355 & 78 \\
b=108.2 .6 & \rho_{0}=45.9\end{array}$ \\
\hline & $\begin{array}{l}6 X_{1} 128 \\
6 Y_{-} 2\end{array}$ & $\begin{array}{lll}1.159 & 054 & 00 \\
1.066 & 144 & 22 \\
0.858 & 324 & 68 \\
\end{array}$ & $\begin{array}{lll}1.127 & 239 & 05 \\
1.016 & 148 & 11 \\
0.873 & 353 & 78 \\
\end{array}$ \\
\hline \multirow[t]{3}{*}{$\begin{array}{l}808 \mathrm{C}-56 \mathrm{R}-2, \\
29-33 \mathrm{~cm} \\
(830 \mathrm{mbsf})\end{array}$} & 9X_2 & \begin{tabular}{lcc}
1.081 & 328 & 03 \\
1.020 & 058 & 03 \\
0.907 & 194 & 86 \\
$\mathrm{~b}=55.0$ & \multicolumn{2}{l}{$\rho_{0}=41.4$}
\end{tabular} & \begin{tabular}{lcc}
1.104 & 329 & 02 \\
1.014 & 059 & 02 \\
0.894 & 198 & 87 \\
b $=62.9$ & \multicolumn{2}{c}{$\rho_{0}=33.5$}
\end{tabular} \\
\hline & 9YN_2 & \begin{tabular}{lll}
1.121 & 346 & 04 \\
0.998 & 077 & 12 \\
0.894 & 238 & 77 \\
$b=82.6$ & \multicolumn{2}{c}{$\rho_{0}=53.4$}
\end{tabular} & $\begin{array}{lll}1.131 & 344 & 06 \\
0.993 & 254 & 01 \\
0.890 & 158 & 85 \\
b=134.6 & \rho_{0}=53.7\end{array}$ \\
\hline & $\begin{array}{l}9 X 22 \& \\
9 Y \bar{N} \_2\end{array}$ & $\begin{array}{lll}1.103 & 339 & 01 \\
1.008 & 069 & 00 \\
0.900 & 158 & 89 \\
\end{array}$ & $\begin{array}{lll}1.131 & 344 & 6 \\
1.009 & 068 & 00 \\
0.890 & 158 & 85 \\
\end{array}$ \\
\hline \multirow[t]{3}{*}{$\begin{array}{l}808 \mathrm{C}-61 \mathrm{R}-5, \\
102-107 \mathrm{~cm} \\
\text { (884 mbsf) }\end{array}$} & $11 \times 2 \_2$ & \begin{tabular}{lcc}
1.104 & 037 & 29 \\
1.037 & 305 & 02 \\
0.873 & 211 & 61 \\
$b=85.5$ & \multicolumn{2}{c}{$\rho_{0}=57.1$}
\end{tabular} & \begin{tabular}{lcc}
1.111 & 039 & 29 \\
1.042 & 306 & 05 \\
0.864 & 207 & 62 \\
$b=87.8$ & \multicolumn{2}{c}{$\rho_{0}=54.7$}
\end{tabular} \\
\hline & $11 Y 2 \_2$ & $\begin{array}{lll}1.155 & 343 & 04 \\
1.042 & 074 & 12 \\
0.831 & 238 & 77 \\
b=106.2 & \rho_{0}=68.1\end{array}$ & $\begin{array}{ccc}1.151 & 359 & 05 \\
1.039 & 089 & 05 \\
0.836 & 225 & 83 \\
b=108.3 & \rho_{0}=66.3\end{array}$ \\
\hline & $\begin{array}{l}11 \mathrm{X} 2 \_28 \\
11 \mathrm{Y} 2 \_2\end{array}$ & $\begin{array}{lll}1.123 & 012 & 27 \\
1.049 & 106 & 08 \\
0.848 & 211 & 61 \\
\end{array}$ & $\begin{array}{lll}1.129 & 138 & 08 \\
1.047 & 102 & 06 \\
0.846 & 230 & 81 \\
\end{array}$ \\
\hline \multirow[t]{3}{*}{$\begin{array}{l}808 \mathrm{C}-70 \mathrm{R}-2, \\
52-56 \mathrm{~cm} \\
(965 \mathrm{mbsf})\end{array}$} & 13XN2_2 & $\begin{array}{lll}1.088 & 104 & 00 \\
1.064 & 014 & 09 \\
0.864 & 198 & 81 \\
b=100.7 & \rho_{0}=87.4\end{array}$ & $\begin{array}{ccc}1.114 & 106 & 00 \\
1.078 & 015 & 09 \\
0.833 & 198 & 81 \\
b=121.6 & \rho_{0}=66.7\end{array}$ \\
\hline & 13YN_2 & $\begin{array}{llr}1.078 & 324 & 00 \\
1.051 & 054 & 07 \\
0.883 & 239 & 84 \\
b=88.6 & \rho_{0}=76.3\end{array}$ & $\begin{array}{lll}1.091 & 342 & 01 \\
1.069 & 072 & 06 \\
0.858 & 239 & 84 \\
b=106.4 & \rho_{0}=58.8\end{array}$ \\
\hline & $\begin{array}{l}13 \mathrm{XN2} 2 \& \\
13 \mathrm{YN} \_2\end{array}$ & $\begin{array}{lll}1.078 & 291 & 01 \\
1.061 & 021 & 08 \\
0.874 & 194 & 82 \\
\end{array}$ & $\begin{array}{lll}1.100 & 112 & 00 \\
1.077 & 022 & 07 \\
0.844 & 199 & 83 \\
\end{array}$ \\
\hline \multirow[t]{3}{*}{$\begin{array}{l}808 \mathrm{C}-89 \mathrm{R}-1, \\
8-12 \mathrm{~cm} \\
(1137 \mathrm{mbsf})\end{array}$} & 16XN_2 & $\begin{array}{lll}1.125 & 212 & 18 \\
1.051 & 120 & 05 \\
0.846 & 012 & 72 \\
b=108.0 & \rho_{0}=74.8\end{array}$ & $\begin{array}{ccc}1.129 & 211 & 17 \\
1.052 & 119 & 05 \\
0.842 & 012 & 72 \\
b=109.8 & \rho_{0}=72.5\end{array}$ \\
\hline & 16Y2N_2 & $\begin{array}{llc}1.156 & 320 & 06 \\
1.091 & 053 & 34 \\
0.793 & 220 & 56 \\
b=105.2 & \rho_{0}=78.3 \\
\end{array}$ & $\begin{array}{lll}1.169 & 319 & 8 \\
1.066 & 053 & 35 \\
0.803 & 218 & 55 \\
\mathrm{~b}=106.1 & \rho_{0}=77.3 \\
\end{array}$ \\
\hline & $\begin{array}{l}16 \mathrm{XN} 22 \& \\
16 Y 2 \bar{N} \_2\end{array}$ & $\begin{array}{lll}1.137 & 182 & 16 \\
1.062 & 088 & 13 \\
0.828 & 322 & 69 \\
\end{array}$ & $\begin{array}{lll}1.120 & 172 & 22 \\
1.079 & 079 & 07 \\
0.827 & 333 & 67 \\
\end{array}$ \\
\hline
\end{tabular}

1. Stretch, $S_{j}=I_{f} / l_{j}$ where $l_{f}$ and $l_{j}$ are final and initial lengths respectively.

2. Azimuth and plunge of principal strain axes in sample coordinates, as shown in Figure 2(C).

3. Constant volumetric background (see text).

4. Uniform density of poles given a random distribution. 


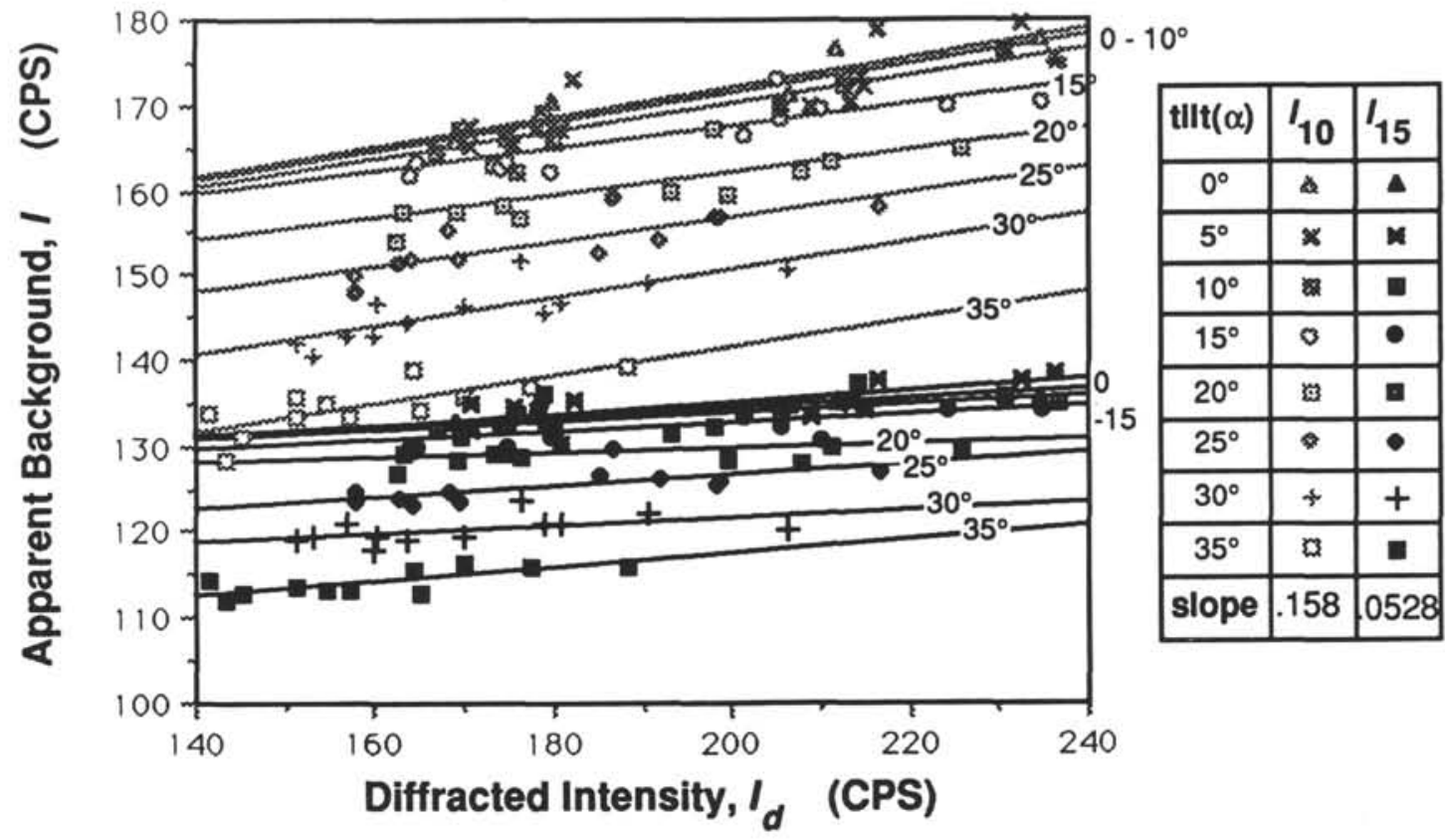

Figure 6. Plot of apparent background $I_{b}(\alpha, \beta)$ against diffracted intensity, $I_{d}(\alpha, \beta)$ for Sample 131-808C-70R-2, $x$-plane. Best-fit lines through data at a given tilt are calculated by regression, yielding nearly parallel lines for each set of apparent background intensities. The degree of apparent background dependence on clay-mineral preferred orientation is indicated by the best-fit slope for each complete data set, found to be 0.158 for $I_{10}(\alpha, \beta)$ and 0.0528 for $I_{15}(\alpha, \beta)$.

$$
A_{2}=\frac{S_{1}{ }^{\prime}-S_{2}{ }^{\prime}}{S_{1}{ }^{\prime}+S_{1}{ }^{\prime}+S_{2}{ }^{\prime}} \cdot 200 \% .
$$

(3) The strain ellipsoid shape factor, K (Flinn, 1962; Ramsay, and Huber 1983) is calculated as

$$
K=\frac{S_{1} / S_{2}-1}{S_{2} / S_{3}-1}
$$

$A_{2}, A_{3}$, and $K$ are plotted in Figure 12. Again, the large circles and squares represent results calculated from the combined scans, while the error bars show the range in values obtained for individual scans. Despite the scatter in the plots, a common pattern becomes apparent. Each plot shows a reversal in trend at mid-depth, somewhere between 700 and 800 mbsf. $A_{3}$ decreases from $32 \%$ to about $25 \%$ at mid-depth, probably as lateral and vertical strain magnitudes increase simultaneously, then increases to about $31 \%$ below the décollement, reflecting the dominance of vertical over lateral shortening. $A_{2}$ varies more smoothly, with a subtle increase from $9 \%$ to $14 \%$ at mid-depth, dropping back to $10 \%$ just above the décollement. Below the décollement, $A_{2}$ reaches a minimum of about $5 \%$, indicating little or no tectonic strain. $K$ values plot in the oblate field for most samples $(K<1)$, ranging from 0.3 to an exaggerated maximum in the prolate field of 1.5 for Section 131-808C-32R-2, and decreasing to 0.2 below the décollement. Strain ellipsoids for Sections 131-808C-32R-2, $-37 \mathrm{R}-1$, and $-56 \mathrm{R}-2$ at mid-depth are closest to the oblate-prolate boundary, presumably as basal planes of the clay minerals rotate slightly away from the plane of bedding into the plane perpendicular to the horizontal shortening direction. Below the décollement, ellipsoids are the most oblate, with $K$ values less than 0.2 , again suggesting no significant horizontal shortening.

\section{DISCUSSION}

The results for lateral strain, $\varepsilon_{2}$, and lateral anisotropy, $A_{2}$, both suggest that accreting sediments in the toe of the Nankai accretionary prism have experienced a measurable degree of lateral ductile short- ening, possibly up to $10 \%$ in the vicinity of the frontal thrust. Sediments below the décollement have experienced little if any lateral shortening. This finding agrees with previous structural studies that show the décollement at this site to be a significant boundary between tectonically deforming sediments above and subducting sediments below (Byrne et al., 1991; Taira, Hill, Firth, et al., 1991). The apparently moderate rotation of principal strain axes suggests that this shortening has been imposed approximately bedding-parallel. Low bedding dips and the symmetric distribution of small-scale deformation structures about the plane of bedding throughout Hole $808 \mathrm{C}$ agree with this observation (Taira, Hill, Firth, et al., 1991).

Generally, neither vertical shortening, $\varepsilon_{3}$ nor horizontal shortening, $\varepsilon_{2}$, show much overall change with depth above the décollement (Figs. 8 and 9), and the magnitudes are lower than expected based on decreasing volume strains determined from porosities (Fig. 10), especially for the lowermost samples. Several possibilities are considered that may explain the unexpectedly low strains and apparent reversals in trend at mid depth:

1. Low background estimates used for the March strain reduction,

2. Incorrect assumptions regarding the state of strain in the prism,

3. Nonrandom initial distribution of clay-minerals,

4. The resetting of clay-mineral fabric by bioturbation, and

5. The breakdown of the March model at high strains.

Because the same approach to background estimation was used for strain determination for all samples, low background estimates would be expressed as low March strains throughout the core, and the resulting volume strains should show a common offset from the porosity-derived volume strains. However, the difference between the two volume strain measures increases steadily with depth, reflecting very little change in March strains with depth. We suggest that errors inherent in background determination will probably result only in relative changes in strain estimates, and therefore cannot explain the anomalies observed.

We have assumed plane strain conditions to be present throughout the prism. However, if strain occurs parallel to the strike of the trench 


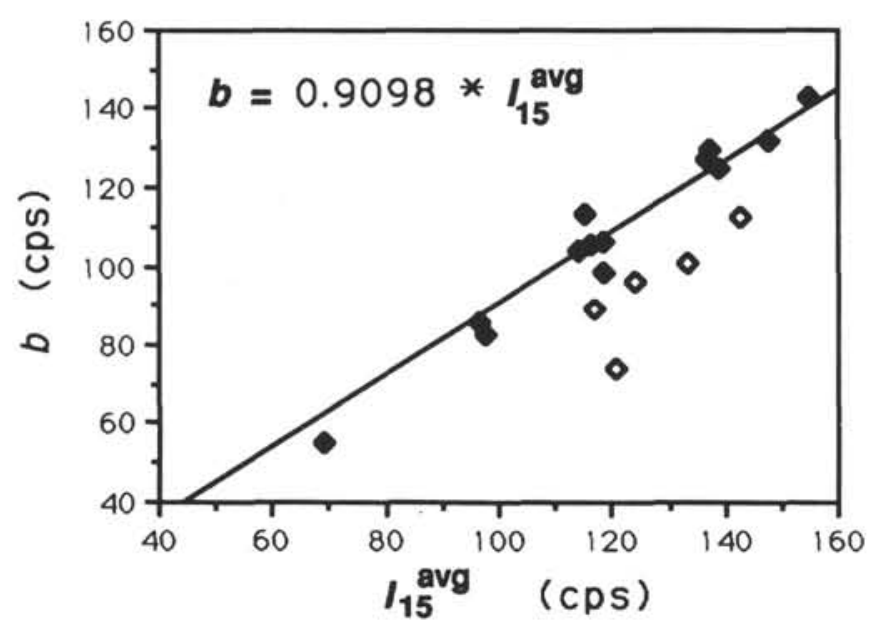

Figure 7. Plot of background obtained iteratively during numerical reduction, $b$ against average apparent background, $I_{15}^{\text {avg }}$ for all data sets, showing best-fit line passing through well-constrained data points (filled diamonds). This suggests that true background values can be estimated at $91 \%$ of $I_{15}^{\mathrm{avg}}$. Open diamonds represent less-reasonable, iteratively-obtained estimates for background.

then the strain normalization procedure would be invalid. In fact, core-scale structures just above the décollement are observed to strike parallel to the trench, suggesting that shortening in that zone may occur parallel to strike (Taira, Hill, Firth, et al., 1991; Lallemant et al., this volume). This explanation, however, is unsatisfactory for the low strains apparent below the décollement, where there are very few deformation structures.

Depositional processes can produce preferred orientations of grains, which if preserved, can yield nonrepresentative estimates for March strains (Holeywell and Tullis, 1975; Etheridge and Oertel, 1979). If basal planes of clay-minerals are initially aligned subparallel to bedding, then further compaction will tend to accentuate the alignment, leading to exaggerated estimates of shortening. Alternatively, if grains are not equidimensional, the long axes may line up parallel to the dominant current (e.g., Niitsuma and Taira, 1986). Rotation of these grains by bedding-parallel shortening will yield high estimates for shortening perpendicular to the long-axis alignment and low estimates in the direction parallel to the alignment. The effects of such initial preferred orientation would produce exaggerated strain estimates, whereas we observe the reverse problem.

Most of these sediments contain abundant evidence of bioturbation, which will disrupt any primary fabric and rerandomize the distribution of grains (Moon and Hurst, 1984; Bryant et al., 1991). The clay-mineral fabric will record only the finite strain incurred after the last randomization (Oertel, 1985b), which may have occurred after sediments have experienced a moderate amount of compaction. Sediments will experience differing degrees of bioturbation depending on sediment type and length of time between disruptive events, e.g. turbidite flows (Wetzel, 1984). If it can be demonstrated that sediments downhole experienced progressively greater amounts of bioturbation as they were deposited farther away from the source of such events; this may in part explain the relatively constant vertical strains.

As the sediments used in this study were already deeply buried by the time tectonic deformation initiated, lateral fabric development should be independent of bioturbation effects. Indeed, lateral anisotropies appear to vary relatively smoothly with depth and are likely to be more representative of true strain.

The assumption inherent in the March model is that sediment deformation occurs through independent mechanical rotation of rigid marker grains within a homogeneously deforming matrix. The results presented here suggest that the March model may break down under certain conditions, perhaps due to grain interactions (e.g., Ildefonse,
1992) or changes in the dominant deformation mechanism with stress (Kanagawa, 1991). The increasing offset between the two measures for volume strain lends support to the idea that there may be a progressive departure from the March model with depth, perhaps associated with variations in sediment composition and grain size, or increasing particle interactions with increasing strain. Such variations may strongly influence the development of clay-mineral preferred orientation, and consequently the estimation of strains by this method. Too few samples are included in this study to permit a systematic analysis of the influence of mineralogy and compaction on the record of March strains, but this is clearly a necessary element of future studies.

Nearly all of the quantities plotted in Figures 9-12 show apparent reversals in trend within the protothrust zone between about 650 and $800 \mathrm{mbsf}$, contributing to the appearance of relatively constant strains with depth. Analogous strain maxima and minima were also recognized at mid-depth from numerical calculations of diffuse strain (i.e., not resolvable seismically) within the protothrust zone along the western transect across the Nankai Prism, site of DSDP Legs 31 and 87A (Morgan, Maniatty, and Karig, 1990). The reversal there was attributed to (1) the complex interplay of sediment strength and porosity, as low-porosity sediments accommodate lateral shortening through vertical extension rather than through additional volume loss, or (2) incomplete decoupling of the accreting and subducting sediments across the décollement. In Hole $808 \mathrm{C}$, however, vertical ductile shortening appears to increase below the mid-depth deflection, rather than decrease as expected if vertical extension overprinted the depositional vertical shortening. This increase in vertical shortening is also concurrent with a subtle decrease in lateral shortening (Fig. 9). Finally, the lack of deformation structures in the subducting sediments, and evidence that tectonic strain is dominantly incurred through pure shear, contradict the proposal that sediments are coupled across the décollement, at least in the vicinity of Site 808 .

One possible explanation for the reversals in trend for sediment strains in Hole $808 \mathrm{C}$ may lie in changing sediment response to tectonic stress. The total deformation in the prism toe includes both brittle and ductile components, and the proportional strains accommodated by each mode may bear inverse relationships to each other. The apparently low ductile strains at depth determined in this study may be countered by increased brittle deformation, indicating a change in the mechanical behavior of the sediment, possibly in response to high pore fluid pressures. Such a change may be reflected in the nonuniform distribution of small-scale deformation structures found in the cores, showing concentrations within discrete zones of deformation (Taira, Hill, and Firth, 1991). Additional fabric analyses and comparative studies of sediment fabric, strain, and mechanical behavior of sediments will be required to assess this possibility, but the results of this study suggest such a change may be significant.

\section{CONCLUSIONS}

The method of X-ray pole figure goniometry has been used to define the clay-mineral fabric of marine sediments at the Nankai Accretionary Margin, and ductile strains have been determined using the March (1932) model relating strain and grain density. The results of this study suggest:

1. Up to $10 \%$ ductile lateral shortening has occurred in the accreting sediments, varying little with depth above the décollement, but displaying a subtle increase to about $700 \mathrm{mbsf}$ and subsequent decrease to the décollement. This strain was most likely imposed parallel to the direction of plate convergence under pure shear, planestrain conditions.

2. Vertical strains determined from this study suggest ductile vertical shortening between about $20 \%$ and $30 \%$, increasing moderately to about $600 \mathrm{mbsf}$, then decreasing to the base of the hole. These estimates, especially for the deepest samples, are lower than expected based on the steady increase with depth in magnitudes of volume 


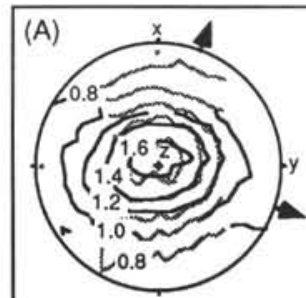

808C-3R-1, 318 mbsf

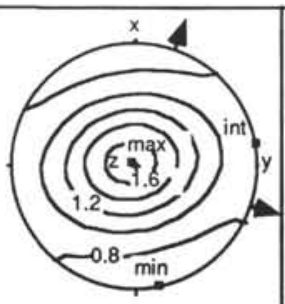

( $\rho-\max : 1.69 \mathrm{mrd})$

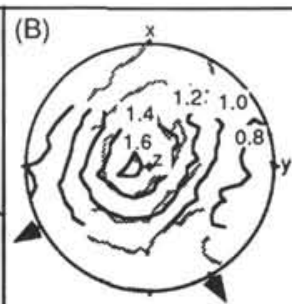

808C-21R-4, 497 mbsf

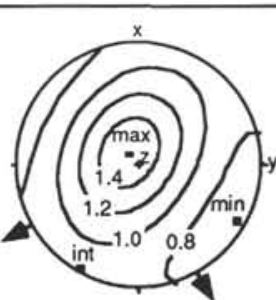

( $\rho$-max: 1.56 mrd $)$
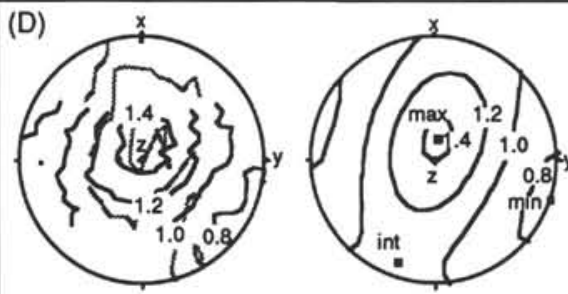

(E)
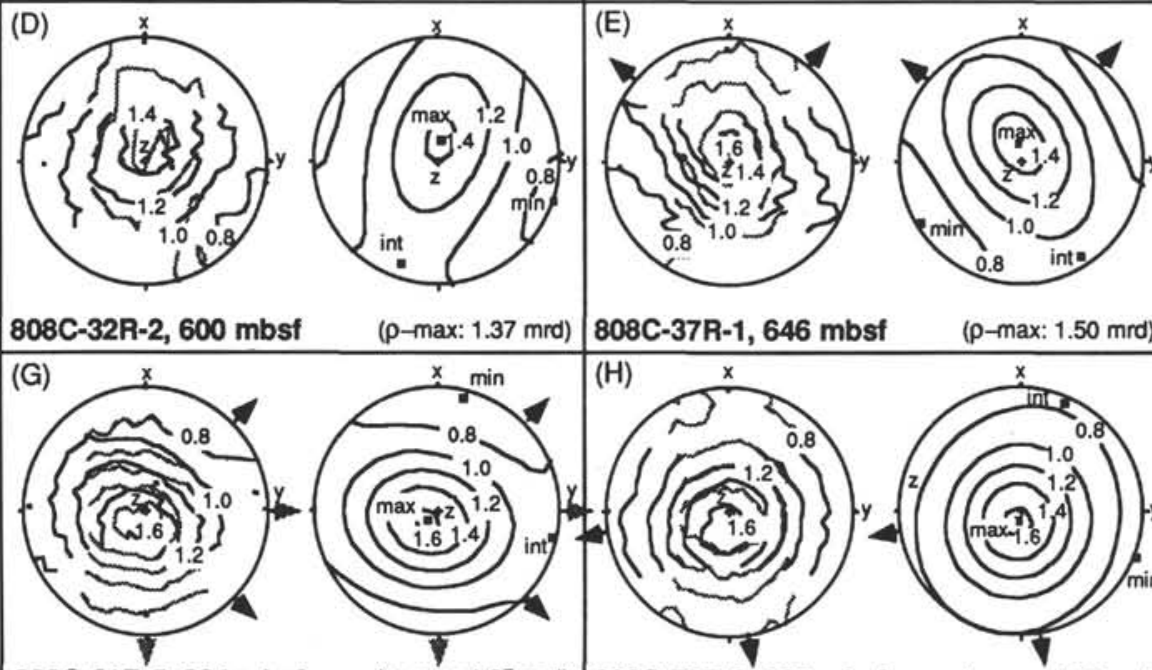

$808 \mathrm{C}-61 \mathrm{R}-5,884 \mathrm{mbsf}$

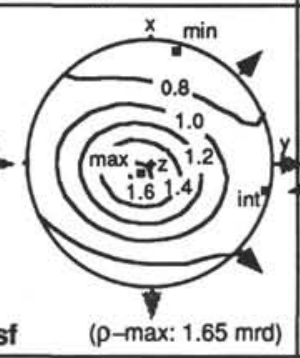

( $\rho-\max : 1.50 \mathrm{mrd})$
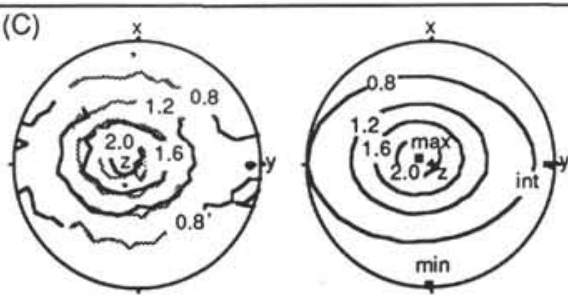

808C-24R-4, 526 mbsf

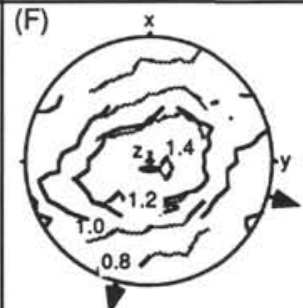

808C-56R-2, $830 \mathrm{mbst}$

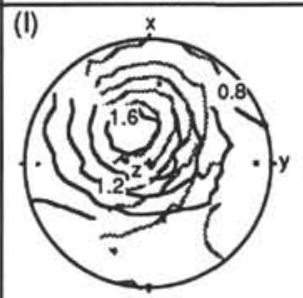

( $\rho-\max : 1.66 \mathrm{mrd}$ ) 808C-89R-1,1137 mbsf
( $\rho-\max : 2.18 \mathrm{mrd})$

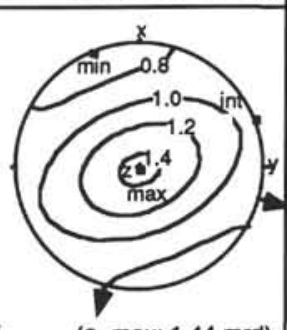

( $\rho-\max : 1.44 \mathrm{mrd})$

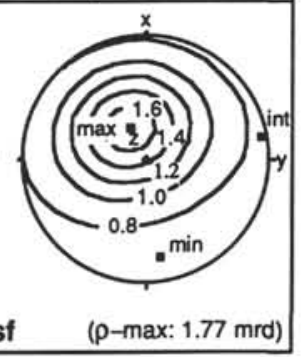

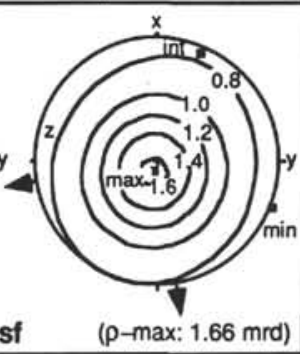

Figure 8. Background- and tilt-corrected pole figures (left) and best-fit density distribution (right) for each sample, contoured in m.r.d. Density distributions for the $x$-plane (black) and $y$-plane (gray) of a sample are plotted together in the sample reference frame. Orientations of maximum, intermediate, and minimum pole densities are indicated on the best-fit distribution, and maximum pole density is given by $\rho_{\max }$. Where paleomagnetic orientations are available, the two possible directions are indicated by arrows along the pole figure perimeter. Four possibilities are available for Section 131-808C-61R-5.

strains (equivalent to vertical strains in the absence of lateral strain) determined from sediment porosities (30\% to $50 \%$ ). The anomalous strain estimates may be a consequence of clay-mineral fabric that has been reset by bioturbation, or may indicate a breakdown of the simplified deformation mechanism assumed for the March model.

3. Subducting sediments exhibit little evidence of lateral strain, consistent with predictions for a uniaxial strain state below the décollement.

4. The reversal in strain trends at mid-depth may reflect changes in sediment response to tectonic stress, altering the relative amounts of brittle and ductile deformation incurred during accretion.

5. The method of X-ray pole-figure goniometry has been shown to be a sensitive recorder of clay-mineral fabric in mildly deformed marine sediments, although several questions regarding the determination of background and absorption corrections remain to be resolved.

The results of this study will be further refined as more samples are analyzed, providing a broader data set with which to systematically study effects of composition, grain size, and depth on fabric development. Future work should also include comparative studies of fabric development and mechanical behavior of sediments under known strain conditions, to examine the relative importance of brittle and ductile modes of deformation in accretionary settings.

\section{ACKNOWLEDGMENTS}

Thanks go to Maura Weathers for instruction and assistance using XRD equipment and software, George Hade for his help in sample preparation and equipment development, John Gephart and Rick
Allmendinger for scientific and programming advice, and Armand Beaudoin and George Johnson for their efforts toward goniometer alignment. Mark Brandon, Gerhard Oertel, Richard Chen, and Ben van der Pluijm are especially recognized for thoughtful reviews and suggestions for improving the manuscript, as well as subsequent helpful discussions. This study was supported in large part by fellowships awarded to Morgan by JOI/USSAC and the Shell Foundation, and funds from NSF Grant EAR-8720754.

\section{REFERENCES}

Baerwald, R.J., Burkett, P.J., and Bennett, R.H., 1991. Techniques for the preparation of submarine sediments for electron microscopy. In Bennett, R.H., Bryant, W.R., and Hulbert, M.H. (Eds.), Microstructure of Finegrained Sediments: From Mud to Shale: New York (Springer-Verlag), 309-320.

Behrmann, J., Brown, K., Moore, J.C., Mascle, A., Taylor, E., Alvarez, F., Andreieff, P., Barnes, R., Beck, C., Blanc, G., Clark, M., Dolan, J.F., Fisher, A., Gieskes, J., Hounslow, M.W., McLellan, P., Moran, K., Ogawa, Y., Sakai, T., Schoonmaker, J., Vrolijk, P., Wilkens, R.H., Williams, C.F., 1988. Evolution of structures and fabrics in the Barbados Accretionary Prism: insights from Leg 110 of the Ocean Drilling Program. J. Struct. Geol., 10:577-591.

Bennett, R.H., Bryant, W.R., and Keller, G.H., 1977. Clay fabric and geotechnical properties of selected submarine sediment cores from the Mississippi Delta. NOAA Prof. Pap., 9.

Borradaile, G.J., 1981. Particulate flow of rock and formation of cleavage. Tectonophysics, 72:305-321.

Bragg, R.H., and Packer, C.M., 1963. Effect of absorption and incoherent scattering on X-ray line profiles. Rev. Sci. Instrum., 34:1202-1207.

1964. Quantitative determination of preferred orientation. J. Applied Phys., 35:1322-1328. 
Brindley, G.W., 1980. Order-disorder in clay mineral structures. In Brindley, G.W., and Brown, G. (Eds.), Crystal Structures of Clay Minerals and Their X-ray Identification. London Mineral. Soc. Monogr., 5:125-195.

Bryant, W.R., Bennett, R.H., Burkett, P., and Rack, F.R., 1991. Microfabric and physical properties characteristics of a consolidated clay section: ODP Site 697, Weddell Sea. In Bennett, R.H., Bryant, W.R., and Hulbert, M.H. (Eds.), Microstructure of Fine-grained Sediments: From Mud to Shale: New York (Springer-Verlag).

Byrne, T., Bruckmann, W., and Owens, W.H., 1991. Correlation of core-scale structural fabrics, acoustic properties, and magnetic anisotropy in an accreting sedimentary sequence (ODP Leg 131, Nankai Trough). Eos, 72:534.

Chen, R., and Oertel, G., 1991. Determination of March strain from phyllosilicate preferred orientation: a semi-numerical method. Tectonophysics, 200:173-185.

Chen, R.T., 1991. Anisotropy of X-ray absorption in a slate: effects on the fabric and March strain determination. J. Geophys. Res., 96:6099-6105.

Cullity, B.D., 1978. Elements of X-ray Diffraction: Reading (Addison-Wesley).

Etheridge, M.A., and Lee, M.F., 1975. Microstructures of slates from Lady Loretta, Queensland, Australia. Geol. Soc. Am. Bull., 86:13-22.

Etheridge, M.A., and Oertel, G., 1979. Strain measurements from phyllosilicates-a precautionary note. Tectonophysics, 60:107-120.

Etheridge, M.A., Paterson, M.S., and Hobbs, B.E., 1974. Experimentally produced preferred orientation in synthetic mica aggregates. Contrib. Mineral. Petrol., 44:275-294.

Flinn, D., 1962. On folding during three-dimensional progressive deformation. Q. J. Geol. Soc. London, 118:385-433.

Gay, N.C. 1968. The motion of rigid particles embedded in a viscous fluid during pure shear deformation of the fluid. Tectonophysics, 5:81-88.

Holeywell, R.C., and Tullis, T.E., 1975. Mineral reorientation and slaty cleavage in the Martinsburg Formation, Lehigh Gap, Pennsylvania. Geol. Soc. Am. Bull., 86:1296-1304.

Hounslow, M.W., 1990. Grain fabric measured using magnetic susceptibility anisotropy in deformed sediments of the Barbados Accretionary Prism: Leg 110. In Moore, J.C., Mascle, A., et al., Proc. ODP, Sci. Results, 110: College Station, TX (Ocean Drilling Program), 257-275.

Ildefonse, B., Lanneau, P., Bouchez L.-L., and Fernandez, A., 1992. Effect of mechanical interactions on the development of shape preferred orientations: a 2-dimensional experimental approach. J. Struct. Geol., 14:73-83.

Jeffery, G.B., 1922. The motion of ellipsoidal particles immersed in a viscous fluid. Proc, R. Soc. London A, 102:161-179.

Kanagawa, K., 1991. Change in dominant mechanism for phyllosilicate preferred orientation during cleavage development in the Kitakami slates of NE Japan. J. Struct. Geol., 13:927-943.

Karig, D.E., 1986. The framework of deformation in the Nankai Trough. In Kagami, H., Karig, D.E., Coulbourn, W.T., et al., Init. Repts. DSDP, 87: Washington (U.S. Government Printing Office), 927-940.

1991. Experimental and observational constraints on the mechanical behaviour in the toes of accretionary prisms. In Knipe, R.J., and Rutter, E.H. (Eds.), Deformation Mechanisms, Rheology and Tectonics. Geol. Soc. Spec. Publ. London, 54:383-398.

Karig, D.E., and Lundberg, N., 1990. Deformation bands from the toe of the Nankai accretionary prism. J. Geophys. Res., 95:9099-9109.

Knipe, R.J., 1981. The interaction of deformation and metamorphism in slates. Tectonophysics, 78:249-272.

1989. Deformation mechanisms-recognition from natural tectonites. J. Struct. Geol., 11:127-146.

Lipshie, S.R., 1984. Development of phyllosilicate preferred orientation in naturally and experimentally deformed rocks [Ph.D. thesis]. Univ. California, Los Angeles.

Lundberg, N., and Moore, J.C., 1986. Macroscopic structural features in Deep Sea Drilling Project cores from forearc regions. In Moore, J.C. (Ed.), Structural Fabrics in Deep Sea Drilling Project Cores From Forearcs. Mem.-Geol. Soc. Am., 166:13-44.

Maltman, A., 1984. On the term "soft sediment deformation." J. Struct. Geol., 6:589-592.

March, A., 1932. Mathematische Theorie der Regelungen nach der Korngestalt bei affiner Deformation. Z. Kristallogr., Mineral., Petrogr., 1:285-297.

Means, W.D., 1976. Stress and Strain: Basic Concepts of Continuum Mechanics for Geologists: New York (Springer-Verlag).
Means, W.D., and Paterson, M.S., 1966. Experiments on preferred orientation of platy minerals. Contrib. Mineral. Petrol., 13:108-133.

Moon, C.F., and Hurst, C.F., 1984. Fabrics of muds and shales: an overview. In Stow, D.A.V., and Piper, D.J.W. (Eds.), Fine-grained Sediments: Deepwater Processes and Facies: Oxford (Blackwell Sci.), 579-593.

Moore, D.M., and Reynolds, R.C., Jr., 1989. X-ray Diffraction and the Identification and Analysis of Clay Minerals: Oxford (Oxford Univ. Press).

Moore, G.F., Shipley, T.H., Stoffa, P.L., Karig, D.E., Taira, A., Kuramoto, S., Tokuyama, H., and Suyehiro, K., 1990. Structure of the Nankai Trough Accretionary Zone from multichannel seismic reflection data. J. Geophys. Res, 95:8753-8765.

Morgan, J.K., Maniatty, A., and Karig, D.E., 1990. Numerical analysis of deformation: Nankai wedge toe. Eos, 71:1593.

Oertel, G., 1970. Deformation of a slaty, lapillar tuff in the Lake District, England. Geol. Soc. Am. Bull., 81:1173-1188.

1983. The relationship of strain and preferred orientation of phyllosilicate grains in rocks - a review. Tectonophysics, 100:413-447.

, 1985a. Reorientation due to grain shape. In Wenk, H.R. (Ed.), Preferred Orientation in Deformed Metals and Rocks: An Introduction to Texture Analysis: London (Academic Press), 259-266.

- 1985b. Phyllosilicate textures in slates. In Wenk, H.R. (Ed.), Preferred Orientation in Deformed Metals and Rocks: An Introduction to Texture Analysis: London (Academic Press), 431-440.

Oertel, G., and Curtis, C.D., 1972. Clay ironstone concretion preserving fabrics due to progressive compaction. Geol. Soc. Am. Bull., 83:2597-2606.

Owens, W.H., 1973. Strain modification of angular density distributions. Tectonophysics, 16:1249-261.

1974. Mathematical model studies on factors affecting the magnetic anisotropy of deformed rocks. Tectonophysics, 24:115-131.

Owens, W.H., and Bamford, D., 1976. Magnetic, seismic, and other anisotropic properties of rock fabrics. Philos. Trans. R. Soc. London, 283:55-68.

Press, W.H., Flannery, B.P., Teukolsky, S.A., and Vetterling, W.T., 1989. Numerical Recipes-The Art of Scientific Computing: Cambridge (Cambridge Univ. Press).

Prior, D.J., and Behrmann, J.H., 1990. Backscatter SEM imagery of finegrained sediments from Site 671, Leg 110-preliminary results. In Moore, J.C., Mascle, A., et al., Proc. ODP, Sci. Results, 110: College Station, TX (Ocean Drilling Program), 257-275.

Ramsay, J.G., and Huber, M.I., 1983. The Techniques of Modern Structural Geology (Vol. 1): Strain Analysis: London (Academic Press).

Siddans, A.W.B., 1976. Deformed rocks and their textures. Philos. Trans. $R$. Soc. London A, 283:43-54.

Taira, A., Hill, I., Firth, J.V., et al., 1991. Proc. ODP, Init. Repts., 131: College Station, TX (Ocean Drilling Program).

Taira, A., and Niitsuma, N., 1986. Turbidite sedimentation in the Nankai Trough as interpreted from magnetic fabric, grain size and detrital modal analyses. In Kagami, H., Karig, D.E., Coulbourn, W.T., et al., Init. Repts. DSDP, 87: Washington (U.S. Govt. Printing Office), 611-632.

Tullis, T.E., 1971. Experimental development of preferred orientation of mica during recrystallization [Ph.D. thesis]. Univ. California, Los Angeles.

Tullis, T.E., and Wood, D.S., 1975. Correlation of finite strain from both reduction bodies and preferred orientation of mica in slate from Wales. Geol. Soc. Am. Bull., 86:632-638.

Wenk, H.R. (Ed.), 1985. Measurement of pole figures. In Wenk, H.R. (Ed.), Preferred Orientation in Deformed Metals and Rocks: An Introduction to Texture Analysis: London (Academic Press), 11-72.

Wetzel, A., 1984. Bioturbation in deep-sea fine-grained sediments: influence of sedimentary texture, turbidite frequency and rates of environmental change. In Stow, D.A.V., and Piper, D.J.W. (Ed.), Fine-grained Sediments: Deepwater Processes and Facies: Oxford (Blackwell Sci. Publ.), 595-608.

Wood, D.S., Oertel, G., Singh, J., and Bennett, H.F., 1976. Strain and anisotropy in rocks. Philos. Trans. R. Soc. London A, 283:27-42.

Date of initial receipt: 1 October 1991

Date of acceptance: 23 April 1992

Ms 131SR-112 


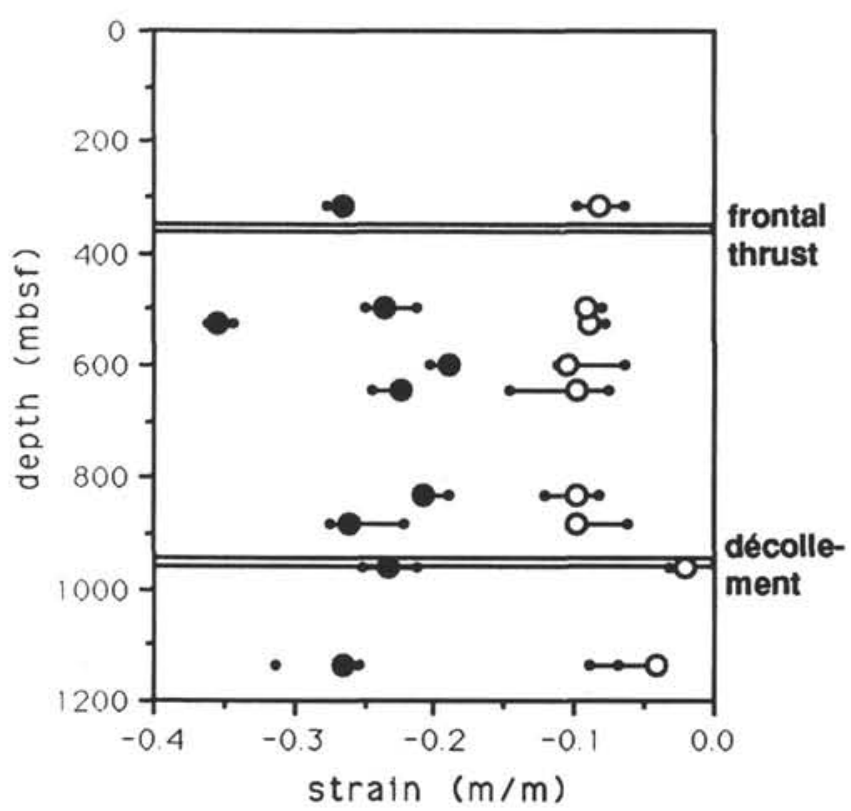

Figure 9. Plot of normalized principal strains vs. depth. Strains are calculated from combined scans of $x$ - and $y$-sections, assuming background to be $91 \%$ of $I_{15}^{\text {avg }}(0)$. Filled circles represent minimum strain, $\varepsilon_{3}$ and open circles are intermediate strain, $\varepsilon_{2 ;}$ maximum strain is assumed to be zero. Error bars are determined from the range of results for individual X-ray scans.

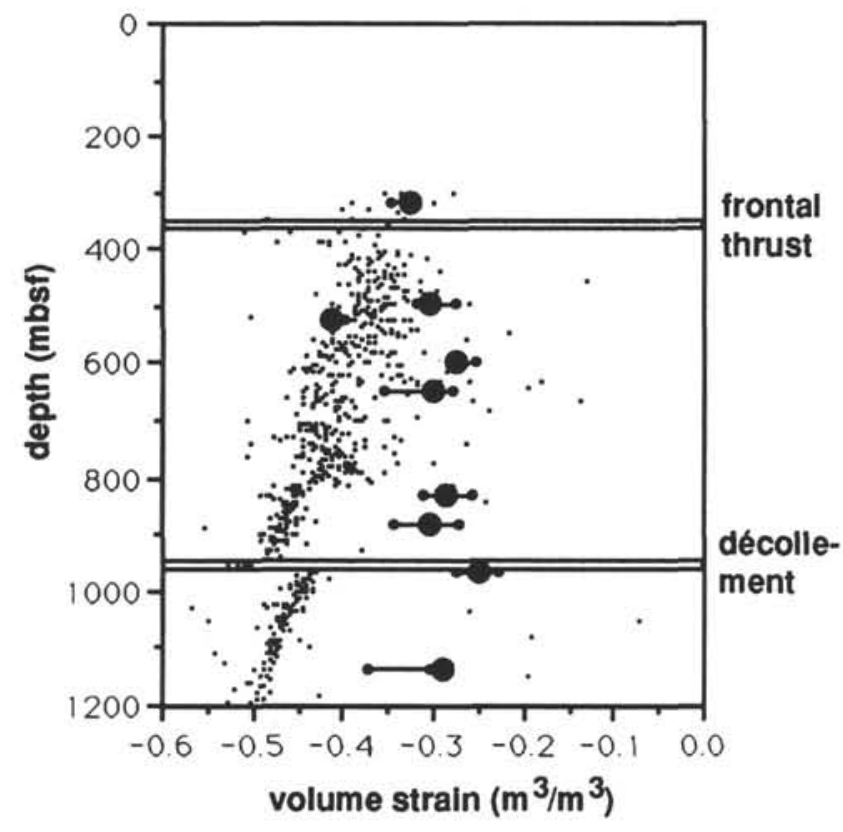

Figure 10. Plot of volume strain vs. depth. Filled circles represent volume strains calculated from normalized March strains (Fig. 9), $\Delta_{m}$, while scattered dots show volume strains calculated from shipboard porosities (assuming an initial porosity of $65 \%), \Delta_{\varphi}$. Error bars are determined from the range of results for individual X-ray scans.

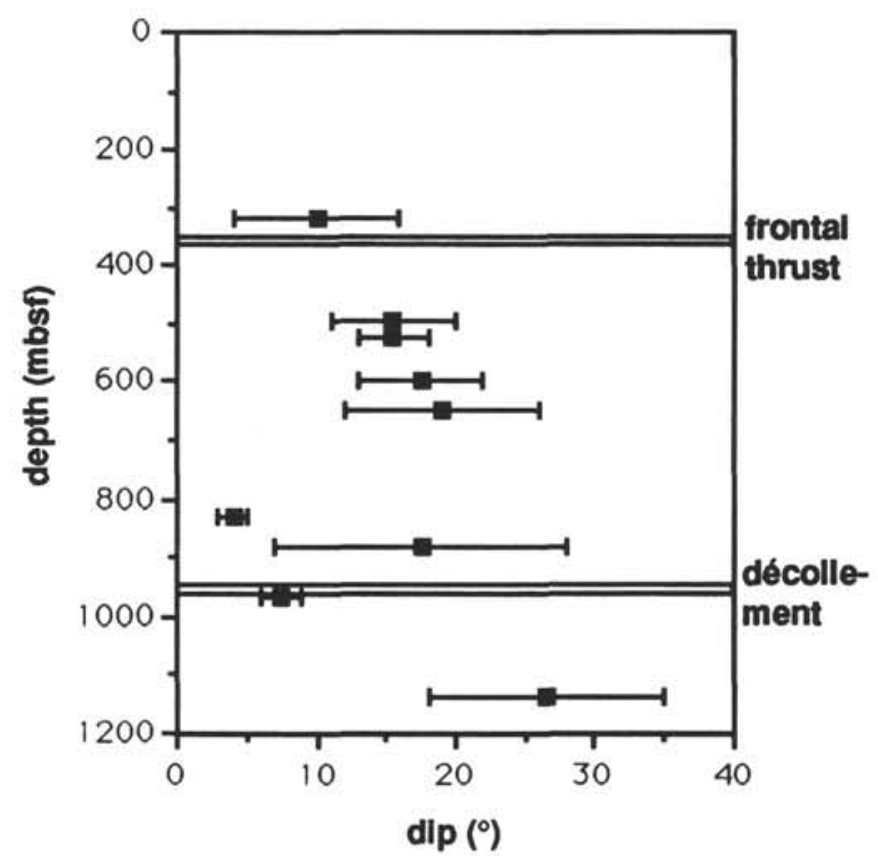

Figure 11. Average dip of the plane containing maximum and intermediate strain axes, showing moderate increase with depth. Error bars are determined from range of results for individual scans. 


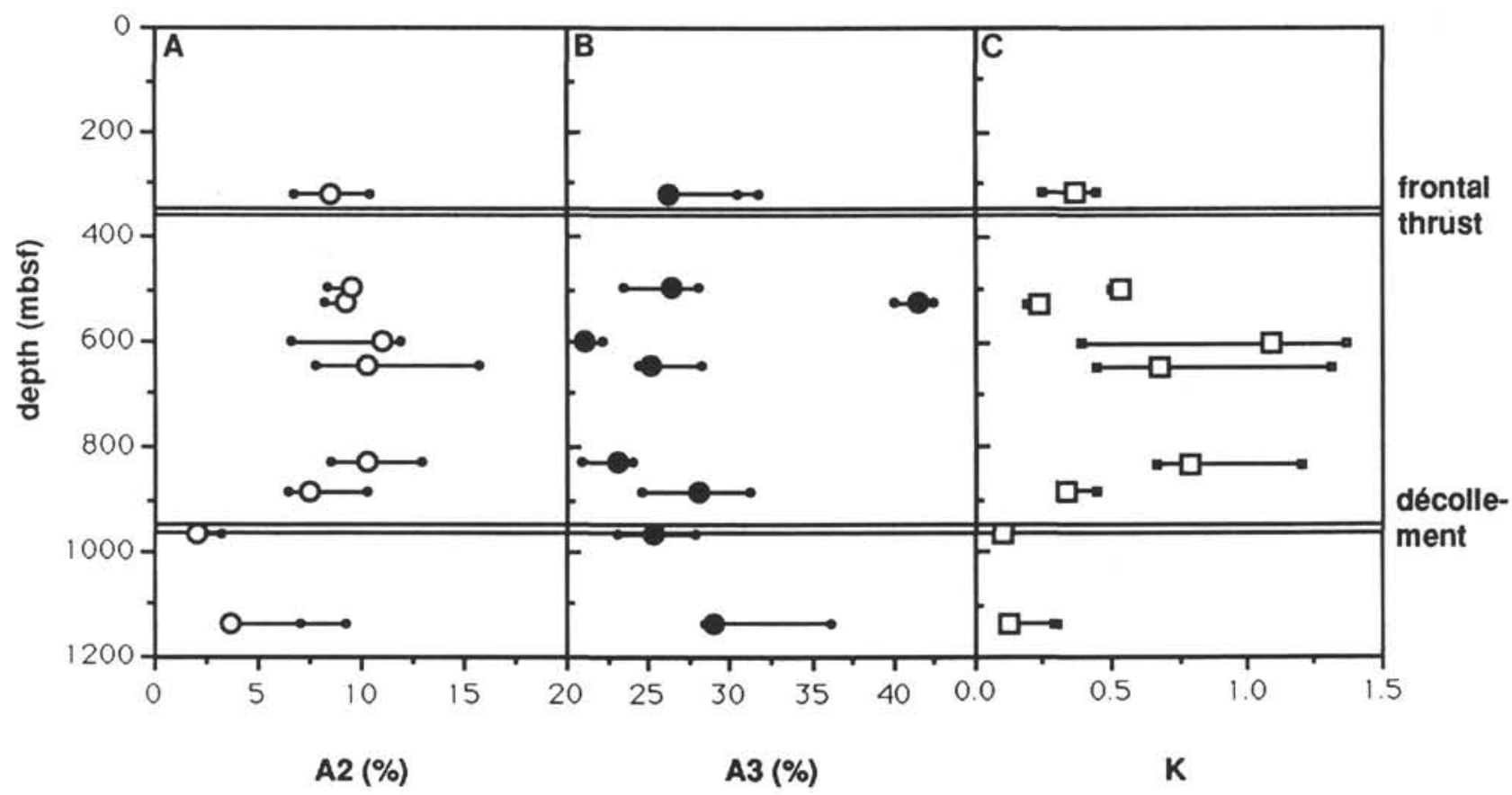

Figure 12. A. Plot of lateral anisotropy, $A_{2}$, vs. depth. B. Plot of total anisotropy vs. depth. C. Plot of strain ellipsoid shape factor, $K$, vs. depth. Error bars are given by range of results from individual scans. 